\title{
Polymer Coated Ferromagnetic Colloids from Well-Defined Macromolecular Surfactants and Assembly into Nanoparticle Chains
}

\author{
Bryan D. Korth, 'Pei Keng,,$^{\dagger}$ Inbo Shim, ${ }^{\ddagger}$ Steven E. Bowles, ${ }^{\dagger}$ Chuanbing Tang, ${ }^{\S}$ Tomasz \\ Kowalewski, Kenneth W. Nebesny, ${ }^{\dagger}$ and Jeffrey Pyun ${ }^{\dagger *}$ \\ ${ }^{\dagger}$ Department of Chemistry, University of Arizona, 1306 E. University Blvd. Tucson Az 85752, \\ tDepartment of Nano and Electronic Physics, Kookmin University, Seoul, Korea, 136-702, \\ ${ }^{\S}$ Department of Chemistry, Carnegie Mellon University, 4400 Fifth Avenue, Pittsburgh, PA \\ 15213 \\ email:.jpyun@email.arizona.edu
}

\section{Supporting Information}

TABLE OF CONTENTS

\section{Experimental}

II. Synthesis of Polymeric Surfactants and Nanoparticles

III. Solid State Characterization of Nanocomposite Compositions (XRD, XPS)

IV. Magnetic Properties (VSM)

V. Additional AFM/MFM images

VI. Binary assemblies of ps-cobalt nanoparticles and $\mathrm{SiO}_{2}$ colloids

VII. References for Supporting Information and Manuscript

\section{EXPERIMENTAL}

Materials and Characterization. 1,2-Dichlorobenzene (DCB), toluene, anhydrous tetrahydrofuran, neutral alumina, 1,4,7,10,13,16-hexaoxacyclooctadecane (18-crown-6), acetonitrile $(\mathrm{ACN})$, acetone, dichloromethane (DCM), hexanes (HEX), methanol $(\mathrm{MeOH})$, anisole, hydrazine hydrate, tributyl tin hydride, magnesium sulfate, and potassium fluoride were purchased from Aldrich and used as received without further purification. Styrene was purchased from Aldrich and passed through a short column of neutral alumina to remove inhibitors prior to use in polymerizations. Dicobaltoctacarbonyl was purchased from Strem Chemicals and used as received. The synthesis of 2,2,5-trimethyl-3-(1-(4'-chloromethyl)phenylethoxy)-4-phenyl-3azahexane (benzyl chloride initiator), ${ }^{1}$ dioctyl phosphonite, ${ }^{2}$ and linear polymers of polystyrene ${ }^{1}$ were prepared following reported methods. Flash chromatography was performed using silica gel from VWR (230-400 mesh) and TLC plates coated with silica gel $\left(60 \mathrm{~F}_{254}\right)$ (Merck). Nuclear magnetic resonance (NMR) was performed using a Bruker DRX $500 \mathrm{MHz}$ FT-NMR spectrometer, operating XWinNMR software (Bruker). Size exclusion chromatography (SEC) was performed in a tetrahydrofuran mobile phase with a Waters 1515 isocratic pump running three $5 \mu \mathrm{m}$ PLgel columns (Polymer Labs, pore sizes $10^{4}, 10^{3}, 10^{2} \AA$ ) with a Waters 2414 differential refractometer and Waters 2487 dual wavelength UV-Vis spectrometer. Molar masses were calculated using the Empower software (Waters) calibrating against low polydispersity linear polystyrene standards. TEM images were obtained on a JEM100CX II transition electron microscope (JEOL) at an operating voltage of $60 \mathrm{kV}$, using in house prepared copper grids $(\mathrm{Cu}$, hexagon, 270 mesh). Analysis of images was carried out using ImagePro 4.1 software (MediaCybernetics). VSM measurements were obtained using a Waker HF 9H electromagnet with a Lakeshore 7300 controller and a Lakeshore 668 power supply. Magnetic measurements were carried out at room temperature $(300 \mathrm{~K})$ and low temperature $(40 \mathrm{~K})$, with a maximum 
applied field of $15 \mathrm{kOe}$, a ramp rate of $33 \mathrm{Oe} / \mathrm{s}$ and a time constant of 0.1 . DSC data was obtained using a 2920 Modulated DSC (TA Instruments) running Thermal Solutions 1.4E (TA Instruments) software. DSC measurements were run in the range of $-35^{\circ} \mathrm{C}$ to $200^{\circ} \mathrm{C}$, at a ramp rate of $10^{\circ} \mathrm{C}$ per minute. TGA analysis was carried out using a TGA Q50 (TA Instruments) instrument and software from TA Instruments. TGA measurements were taken from $20^{\circ} \mathrm{C}$ to $900^{\circ} \mathrm{C}$ at a ramp rate of $20^{\circ} \mathrm{C}$ per minute. XRD measurements were performed using the $\mathrm{X}$ 'pert $\mathrm{X}$-ray diffractometer (PW1827) (Phillips) at room temperature with a CuKa radiation source at 40 $\mathrm{kV}$ and $30 \mathrm{~mA}$. The scan angle was from 30 to 80 degrees with a scan size of 0.2 degrees and a scan time of 0.5 seconds per 0.2 degrees. XPS characterization was performed on a KRATOS 165 Ultra photoelectron spectrometer, using a monochromatic $\mathrm{Al} \mathrm{K \alpha}$ radiation source. Magnetic force microscopy (MFM) studies were carried out with the aid of a Nanoscope III-M system (Digital Instruments, Santa Barbara, CA), equipped with a J-type "vertical engage" scanner. The MFM observations were performed at room temperature in air using silicon cantilevers with nominal spring constant of $1-5 \mathrm{~N} / \mathrm{m}$ and nominal resonance frequency of $24-33 \mathrm{kHz}(\mathrm{Co} / \mathrm{Cr}$ coated etched silicon probes). Topographic images were acquired with the cantilever oscillating at a frequency at which the oscillation amplitude was equal to $50 \%$ of amplitude on resonance. Typically, the ratio of cantilever operating amplitude $A$ to free amplitude $A_{\mathrm{o}}$ ranged from 0.7 to 0.8 with $A_{\mathrm{o}}=2 \mathrm{~V}$ (uncalibrated detector signal). Non-contact MFM images were acquired simultaneously with topography using interleaved lift mode, and frequency or phase shift detection. In the interleaved MFM scan, the cantilever was oscillated at its resonance frequency with the amplitude ranging from 7 to $14 \mathrm{~V}$, and was scanned at the lift height of $150 \mathrm{~nm}$ above the previously recorded topographic profile. High lift heights and cantilever amplitudes employed here were shown by other authors to assure, respectively, good separation of magnetic effects from topography and improved signal-to-noise ratio. ${ }^{3}$ All the images were acquired at a scan frequency of $1 \mathrm{~Hz}$. Before imaging, the tips were magnetized with an external magnet and checked by imaging a standard magnetic recording tape. AFM/MFM samples were prepared by drop casting colloidal dispersions (1-wt\% in toluene) onto carbon coated mica. Field aligned samples were prepared in a similar fashion between the poles of a horseshoe magnet $(100 \mathrm{mT})$.

Preparation of 2,2,5-trimethyl-3-(1-(4'-phthalimidemethyl)phenylethoxy)-4-phenyl-3azahexane (benzyl phthalimide initiator) (1). To a $25 \mathrm{~mL}$ round bottom flask equipped with a magnetic stir bar was added benzyl chloride initiator $(2.00 \mathrm{~g}, 5.36 \mathrm{mmol})$, potassium phthalimide $(1.41 \mathrm{~g}, 7.61 \mathrm{mmol}), 18$-crown-6 $(0.20 \mathrm{~g}, 0.76 \mathrm{mmol})$, and acteonitrile $(10 \mathrm{~mL})$. The reaction was stirred at $50^{\circ} \mathrm{C}$ overnight under argon. The reaction was then filtered through a coarse glass frit, washed with acetone to remove any solids, and concentrated in vacuo to yield a yellow oil. The yellow oil was purified via flash chromatography with an initial hexanes/dichloromethane elution mixture of 4:1 with a gradual increase to a 1:1 mixture yielding a yellow oil $(2.06 \mathrm{~g}, 79.4 \%)\left(\mathrm{R}_{\mathrm{f}}=\right.$ 0.20, 1:1 Hexanes/Dichloromethane). ${ }^{1} \mathrm{H}$ NMR (500 MHz, $\mathrm{CDCl}_{3}$, diastereomers) $\delta 7.83(2 \mathrm{H}, \mathrm{dd}$, $\mathrm{J}=5.4,3.1 \mathrm{~Hz}, \mathrm{ArH}), \delta 7.69(2 \mathrm{H}, \mathrm{dd}, \mathrm{J}=5.4,3.1 \mathrm{~Hz}, \mathrm{ArH}), \delta 7.412-7.3(4 \mathrm{H}, \mathrm{m}, \operatorname{ArH}), \delta 7.26-7.1$ $(5 \mathrm{H}, \mathrm{m}, \mathrm{ArH}), \delta 4.9-4.75\left(3 \mathrm{H}, \mathrm{m}, \mathrm{CH}+\mathrm{CH}_{2}\right), \delta 3.39,3.28(1 \mathrm{H}, \mathrm{d}, \mathrm{J}=10.7 \mathrm{~Hz}, \mathrm{CH}$, diastereomers $)$, $\delta$ 2.34-2.23 (1H, m, CH), $\delta 1.57,1.495\left(3 \mathrm{H}, \mathrm{d}, \mathrm{J}=6.6 \mathrm{~Hz}, \mathrm{CH}_{3}\right.$ diastereomers $), \delta 1.273,0.88$, $0.52,0.16\left(6 \mathrm{H}, \mathrm{d}, \mathrm{J}=6.4 \mathrm{~Hz}, \mathrm{CH}_{3}\right.$, diastereomers $), \delta 1.014,0.765\left(9 \mathrm{H}, \mathrm{s}, \mathrm{CH}_{3}\right.$, diastereomers $)$; ${ }^{13} \mathrm{C}$ NMR (125 MHz, $\mathrm{CDCl}_{3}$, diastereomers) $\delta 168.0,145.3,144.5,142.3,142.1,135.3,134.5$, $133.9,132.1,130.9,130.8,128.3,127.3,127.1,126.3,126.1,123.3,83.0,82.1,72.1,60.5,53.4$, 41.4, 32.0, 31.6, 28.4, 28.2, 24.7, 23.0, 22.1, 21.9, 21.1, 21.0. $\mathrm{m} / \mathrm{z}$ found (Low Res, FAB): 485.07 .

Preparation of 2,2,5-trimethyl-3-(1-(4'-dioctylphosphorylmethyl)phenylethoxy)-4-phenyl-3azahexane (benzyl DOPO initiator) (2). To a $100 \mathrm{~mL}$ three neck round bottom flask equipped 
with a magetic stir bar and condenser was added dioctylphosphine oxide (3.29 g, $12.03 \mathrm{mmol})$ and sodium hydride $(0.33 \mathrm{~g}, 14.03 \mathrm{mmol})$ in anhydrous THF $(30 \mathrm{~mL})$. The reaction was heated under argon at $50^{\circ} \mathrm{C}$ for 30 minutes followed by the slow dropwise addition of benzyl chloride initiator $(3.00 \mathrm{~g}, 8.021 \mathrm{mmol})$ in anhydrous THF $(20 \mathrm{~mL})$ over a period of 30 minutes. The reaction was heated at $50^{\circ} \mathrm{C}$ overnight under argon. After cooling to room temperature, the reaction was quenched with $\mathrm{H}_{2} \mathrm{O}(10 \mathrm{~mL})$ and then concentrated in vacuo to give an oil. The oil was dissolved in dichloromethane, dried over $\mathrm{MgSO}_{4}$, and re-concentrated in vacuo. The oil was purified via flash chromatography with an initial eluent of dichloromethane gradually increasing to a 10:1 mixture of dichloromethane/methanol yielding a slightly yellow oil $(4.17 \mathrm{~g}, 84.9 \%)\left(\mathrm{R}_{\mathrm{f}}\right.$ $=0.34,10: 1$ Dichloromethane/Methanol). ${ }^{1} \mathrm{H}$ NMR $\left(500 \mathrm{MHz}, \mathrm{CDCl}_{3}\right.$, diastereomers $) \delta 7.48$ $7.36(2 \mathrm{H}, \mathrm{m}, \mathrm{ArH}), \delta$ 7.28-7.12 (7H, m, ArH), $\delta 4.88(1 \mathrm{H}, \mathrm{m}, \mathrm{CH}), \delta 3.35,3.28(1 \mathrm{H}, \mathrm{d}, \mathrm{J}=10.6$ $\mathrm{Hz}, \mathrm{CH}$, diastereomers), $\delta 3.15,3.09\left(2 \mathrm{H}, \mathrm{d}, \mathrm{J}=15 \mathrm{~Hz}, \mathrm{CH}_{2}\right.$, diastereomers $), \delta 2.34-2.30(1 \mathrm{H}, \mathrm{m}$, $\mathrm{CH}), \delta 1.61-1.48\left(12 \mathrm{H}, \mathrm{m}, \mathrm{CH}_{3}+\mathrm{CH}_{2}\right), \delta 1.42-1.19\left(22 \mathrm{H}, \mathrm{m}, \mathrm{CH}_{2}\right), \delta 1.04,0.75\left(9 \mathrm{H}, \mathrm{s}, \mathrm{CH}_{3}\right.$ diastereomers), $\delta 0.93-0.82\left(6 \mathrm{H}, \mathrm{m}, \mathrm{CH}_{2}+\mathrm{CH}_{3}\right) \delta 0.54,0.20\left(3 \mathrm{H}, \mathrm{d}, 6.6 \mathrm{~Hz}, \mathrm{CH}_{3}\right.$ diastereomers). ${ }^{13} \mathrm{C}$ NMR $\left(125 \mathrm{MHz}, \mathrm{CDCl}_{3}\right.$, diastereomers) $\delta 144.3,143.7,142.3,142.0,131.5,131.4,130.9$, $130.8,129.0,127.5,127.3,127.1,126.7,126.3,126.1,83.0,82.5,72.3,72.0,60.6,60.3,36.4$, $36.3,35.9,35.8,32.0,31.8,31.7,31.2,31.1,29.0,28.4,28.2,27.7,27.4,27.2,26.9,24.4,23.2$, 22.6, 22.2, 22.0, 21.6, 21.1, 21.0, 14.0. $\mathrm{m} / \mathrm{z}$ found (Low Res, FAB): 612.2.

Preparation of benzyl phthalimide end functional polystyrene (3a). To a $10 \mathrm{~mL}$ Schlenk flask equipped with stir bar was added $1(0.23 \mathrm{~g}, 0.48 \mathrm{mmol})$, styrene $(4.00 \mathrm{~g}, 38.4 \mathrm{mmol})$, and anisole $(3.00 \mathrm{~g})$. The reaction was bubbled with argon for 20 minutes followed by three freezepump-thaw cycles. The Schlenk flask was then submerged into an oil bath $\left(125^{\circ} \mathrm{C}\right)$ for 12 hours. The reaction was diluted with dichloromethane $(1 \mathrm{~mL})$ and precipitated into stirring methanol $(500 \mathrm{~mL})$. The precipitation procedure was performed twice followed by drying in vacuo, to yield a white powder $\left(3.00 \mathrm{~g}, \mathrm{M}_{\mathrm{n}}=4950, \mathrm{M}_{\mathrm{w}} / \mathrm{M}_{\mathrm{n}}=1.09,89 \%\right) .{ }^{1} \mathrm{H} \mathrm{NMR}\left(500 \mathrm{MHz}, \mathrm{CDCl}_{3}\right) \delta$ $7.82(\mathrm{~b}, \mathrm{ArH}), \delta 7.66$ (b, ArH), $\delta$ 7.1-6.5 (bm, ArH), $\delta 4.77\left(\mathrm{~b}, \mathrm{CH}_{2}\right), \delta$ 2.4-1.2 (bm, $\left.\mathrm{CH}+\mathrm{CH}_{2}\right), \delta$ 1.05-0.7 (bm, $\left.\mathrm{CH}_{3}\right), \delta$ 0.6-0.4 (bm, $\left.\mathrm{CH}_{3}\right)$.

Removal of alkoxyamine chain end functionality with tributyl tin hydride (3b). To a $10 \mathrm{ml}$ Schlenk flask equipped with stir bar was added 3a $\left(\mathrm{M}_{\mathrm{n}}=4,950 \mathrm{~g} / \mathrm{mol}\right)(1.00 \mathrm{~g}, 0.208 \mathrm{mmol})$, xylene $(2.00 \mathrm{~g})$, and tributyl tin hydride $(0.30 \mathrm{~g}, 1.042 \mathrm{mmol})$. The reaction solution was bubbled with argon for 20 minutes and was followed by three freeze-pump-thaw cylces. The Schlenk flask was then submerged into an oil bath $\left(125^{\circ} \mathrm{C}\right)$ for 12 hours. The reaction was precipitated into stirring methanol $(600 \mathrm{ml})$ to yield a slightly yellow solid $(0.78 \mathrm{~g}, 82 \%$ yield $)$. Tin byproduct was removed by dissolving the polymer in dichloromethane and passing the solution through a short $\mathrm{SiO}_{2} / \mathrm{KF}$ column ( $10 \% \mathrm{KF}$ by weight) in a manner previously reported. ${ }^{4}$ Residual tin byproduct indicated by NMR to be less than $5 \% .{ }^{1} \mathrm{H}$ NMR $\left(500 \mathrm{MHz}, \mathrm{CDCl}_{3}\right) \delta 7.82(\mathrm{~b}, \mathrm{ArH}), \delta$ 7.66 (b, ArH), $\delta$ 7.3-6.3 (bm, ArH), $\delta 4.77\left(\mathrm{~b}, \mathrm{CH}_{2}\right), \delta 2.4-1.2\left(\mathrm{bm}, \mathrm{CH}+\mathrm{CH}_{2}\right), \delta 1.0-0.9\left(\mathrm{~b}, \mathrm{CH}_{3}\right)$.

Reduction of phthalimide functionality with hydrazine hydrate (3c). To a screw cap scintillation vial equipped with a stir bar was added $3 \mathbf{b}\left(\mathrm{M}_{\mathrm{n}}=4,950 \mathrm{~g} / \mathrm{mol}\right)(1.50 \mathrm{~g}, 0.306 \mathrm{mmol})$ dissolved in THF $(10 \mathrm{~mL})$. Methanol $(0.63 \mathrm{~g})$ was added dropwise followed by addition of hydrazine hydrate $(0.200 \mathrm{~g}, 3.99 \mathrm{mmol})$. The reaction solution was stirred at room temperature for 24 hours, after which a white precipitate could be seen in the reaction media. The reaction mixture was concentrated and redissolved in tetrahydrofuran, followed by precipitation into stirring methanol $(500 \mathrm{ml})$. The precipitation sequence was carried out twice followed by drying in vacuo to yield benzyl amine end-functional polystyrene as a white powder $(1.25 \mathrm{~g}, 86 \%) .{ }^{1} \mathrm{H}$ NMR (500 MHz, $\left.\mathrm{CDCl}_{3}\right) \delta$ 7.3-6.3 (bm, ArH), $\delta$ 3.85-3.75 (b, $\left.\mathrm{CH}_{2}\right), \delta$ 2.4-1.2 (bm, $\left.\mathrm{CH}+\mathrm{CH}_{2}\right), \delta$ 1.05-0.9 (b, $\left.\mathrm{CH}_{3}\right)$. 
Preparation of benzyl DOPO end functional polystyrene (4a). To a $10 \mathrm{~mL}$ Schlenk flask equipped with stir bar was added $2(0.23 \mathrm{~g}, 0.38 \mathrm{mmol})$, styrene $(2.10 \mathrm{~g}, 20.19 \mathrm{mmol})$, and anisole $(1.10 \mathrm{~g})$. The reaction solution was bubbled with argon for 20 minutes and was followed by three freeze-pump-thaw cycles. The schlenk flask was then submerged into an oil bath $\left(125^{\circ}\right.$ C) for 12 hours. The reaction was diluted with dichloromethane $(1 \mathrm{~mL})$ and precipitated into stirring $\mathrm{MeOH}(500 \mathrm{~mL})$. The precipitation was performed two times and was dried in vacuo to yield a white powder $\left(1.7 \mathrm{~g}, 88 \% ; \mathrm{M}_{\mathrm{n}}=5,100 ; \mathrm{M}_{\mathrm{w}} / \mathrm{M}_{\mathrm{n}}=1.10 ;\right) .{ }^{1} \mathrm{H} \mathrm{NMR}\left(500 \mathrm{MHz}, \mathrm{CDCl}_{3}\right.$, diastereomers) $\delta$ 7.3-6.3 (bm, $\mathrm{ArH}), \delta 3.1-3.0\left(\mathrm{~b}, \mathrm{CH}_{2}\right), \delta 2.4-1.2\left(\mathrm{bm}, \mathrm{CH}+\mathrm{CH}_{2}\right), \delta 1.05-0.7(\mathrm{bm}$, $\left.\mathrm{CH}_{3}\right), \delta$ 0.6-0.5 (bm, $\left.\mathrm{CH}_{3}\right)$.

Removal of alkoxyamine chain end functionality with tributyl tin hydride (4b). To a $10 \mathrm{ml}$ Schlenk flask equipped with stir bar was added $4 \mathbf{a}\left(\mathrm{M}_{\mathrm{n}}=5,300 \mathrm{~g} / \mathrm{mol}\right)(1.0 \mathrm{~g}, 0.189 \mathrm{mmol})$, xylene $(2.00 \mathrm{~g})$, and tributyl tin hydride $(0.274 \mathrm{~g}, 0.943 \mathrm{mmol})$. The reaction was then bubbled with argon for 20 minutes and was followed by three freeze-pump-thaw cycles applying a final argon backfill to provide positive atmosphere. The Schlenk flask was then submerged into an oil bath $\left(125^{\circ} \mathrm{C}\right)$ for 12 hours. The reaction was precipitated into stirring $\mathrm{MeOH}(600 \mathrm{ml})$ to yield benzyl DOPO end functional polystyrene as slightly yellow solid $(0.754 \mathrm{~g}, 75 \%$ yield). Tin byproducts were removed by dissolving polymer in dichloromethane and passing through a short $\mathrm{SiO}_{2} / \mathrm{KF}$ column $(10 \% \mathrm{KF}$ by weight $)$ in manner previously reported. ${ }^{3}$ Residual tin byproducts were found to be less than $5 \%$ by NMR. ${ }^{1} \mathrm{H}$ NMR $\left(500 \mathrm{MHz}, \mathrm{CDCl}_{3}\right) \delta$ 7.3-6.3 (bm, ArH), $\delta 3.1-$ $3.0\left(\mathrm{~b}, \mathrm{CH}_{2}\right), \delta$ 2.44-1.3 (bm, $\left.\mathrm{CH}+\mathrm{CH}_{2}\right), \delta 1.05-0.85\left(\mathrm{bm}, \mathrm{CH}_{3}\right)$.

Preparation of polystyrene coated cobalt nanoparticles (5). To a three neck round bottom flask with a magnetic stir bar and condenser was added end-functional polystyrenes $3 \mathbf{c}(0.080 \mathrm{~g}$, $0.017 \mathrm{mmol})$ and $\mathbf{4 b}\left(0.020 \mathrm{~g}, 4.1 \times 10^{-3} \mathrm{mmol}\right)$ in dichlorobenzene $(12 \mathrm{~mL})$. The flask was flushed with argon for 10 minutes followed by submersion into an oil bath $\left(185^{\circ} \mathrm{C}\right)$ for 10 minutes under argon. A solution of dicobaltoctacarbonyl $(0.40 \mathrm{~g}, 1.17 \mathrm{mmol})$ in dichlorobenzne $(4 \mathrm{~mL})$ was injected into a refluxing, stirring solution over a period of 30 seconds. The evolution of a gas was observed. The reaction was heated for 15 minutes and was cooled to room temperature with continuous stirring under argon. The collected reaction mixture was then precipitated into stirring hexanes $(500 \mathrm{~mL})$. The precipitate was collected by sedimentation using a standard AlNiCo magnet followed by decanting of the hexanes phase. The resulting precipitate was then dried in vacuo to give a black powder (5) (yield: $0.150 \mathrm{~g}$ ) that was soluble in a wide range of nonpolar solvents (e.g. toluene, THF, $\mathrm{CH}_{2} \mathrm{Cl}_{2}$ ) and was responsive to an external magnetic field.

Preparation of polystyrene coated cobalt nanoparticles for TEM imaging and analysis. Polystyrene coated cobalt colloids in powder form $(5 \mathrm{mg})$ were dispersed in organic solvent (20 $\mathrm{mL}$ ) from which a drop of solution was placed onto a carbon coated strip of mica and allowed to dry. Organic solvents, toluene and tetrahydrofuran, as well as halogenated solvents, dichloromethane and chlorobenzene, were able to disperse the polystyrene coated cobalt nanoparticles to give colloidal dispersions that were stable over a period of several months prior to the submission of the manuscript. The carbon coating of the mica strip was lifted onto a droplet of nanopure water followed by lifting of the carbon layer onto a copper grid. The copper grid was allowed to dry prior to imaging. Images of the polystyrene coated cobalt nanoparticles indicated a cobalt core size of $15.0 \mathrm{~nm} \pm 1.5 \mathrm{~nm}$ with a polymer shell of $2 \mathrm{~nm}$ (Figure S-1,2). It was observed in the TEM images that polymer coated nanoparticles self assembled into 1-D fiber like structures extending over microns in length, both in the absence and presence of an external magnetic field during drying. 

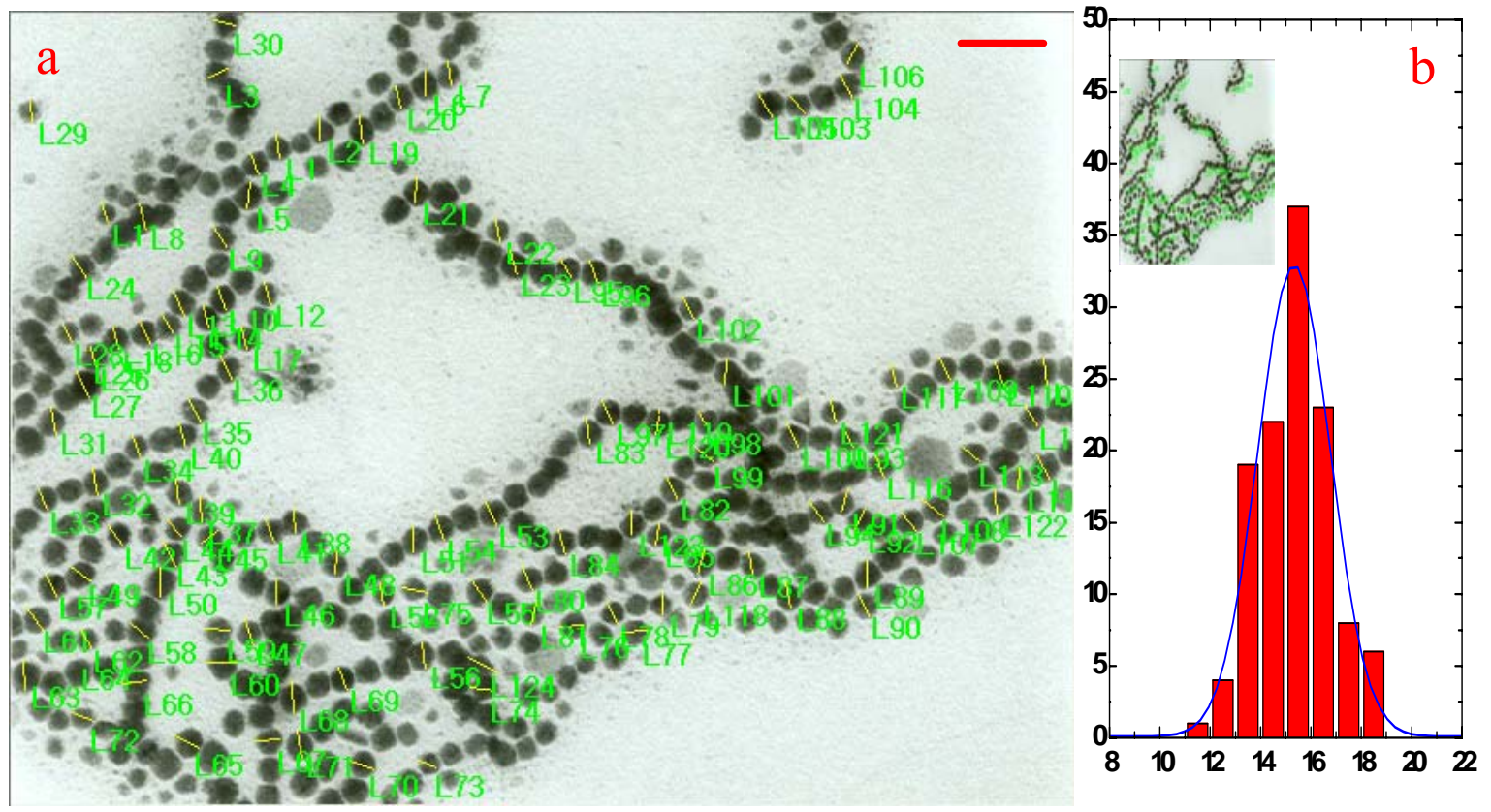

Figure S-1. a) TEM Image of cobalt nanoparticles prepared from mixed polymer surfactant system. Particles analyzed are labeled and indicated by yellow lines. Bar $=50 \mathrm{~nm}$ b) Bar graph of particle distribution obtained from a, analysis indicates particle size of $15 \pm 1.5 \mathrm{~nm}$. 


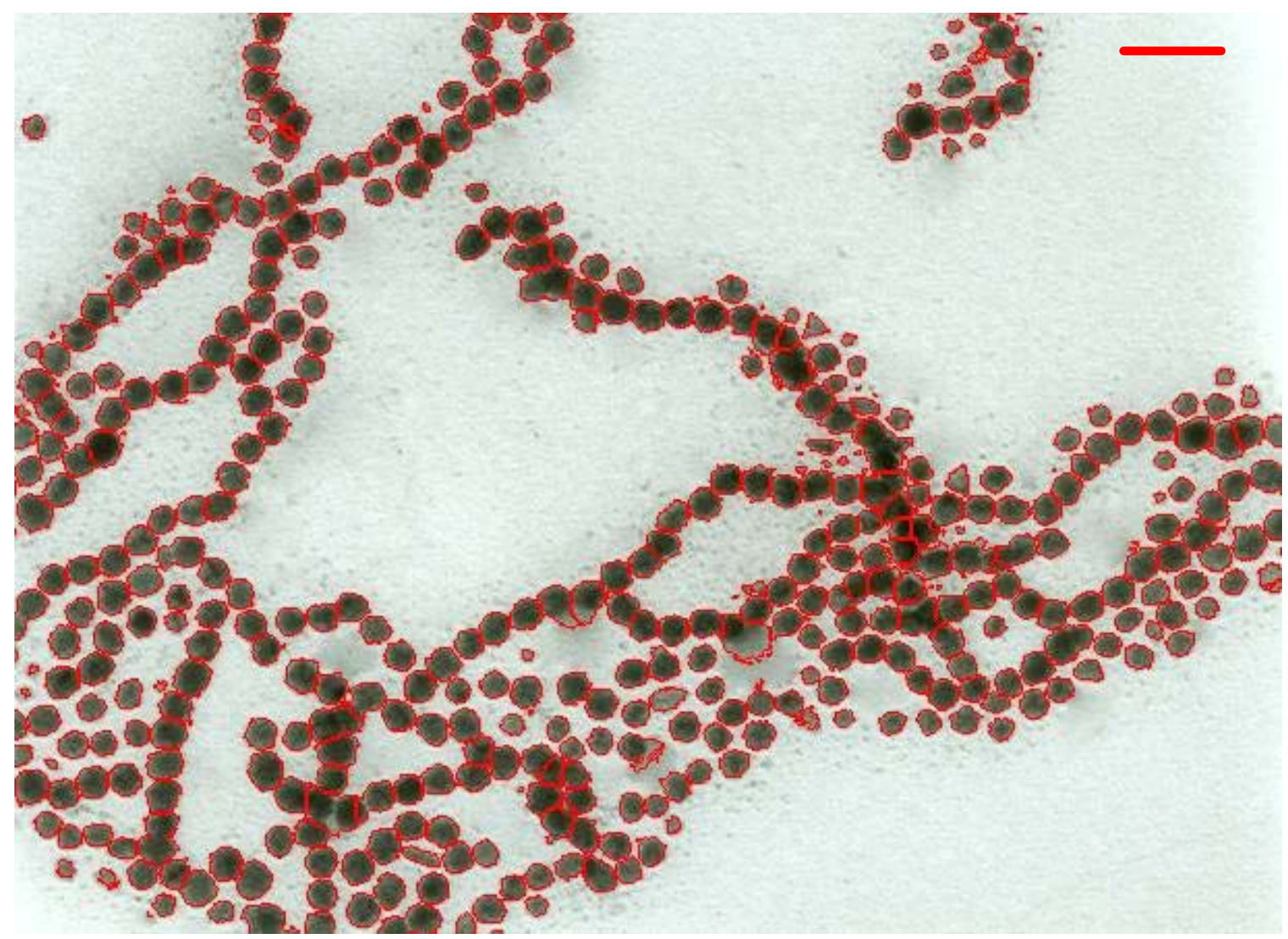

Figure S-2. Indication of particles used in analysis of $5 k$ polystyrene coated cobalt nanoparticles, count 466. Bar $=50 \mathrm{~nm}$

\section{Synthesis of Polymeric Surfactants and Coated Colloids (Scheme S-1)}

The synthesis of amine functional $\mathrm{pS}$ was achieved by alkylation of benzyl chloride functional alkoxyamine (2,2,5-trimethyl-3-(1-(4'-chloromethyl)phenylethoxy)-4-phenyl-3-azahexane) with potassium phtalimide, yielding alkoxyamine 1 , which was then used as an initiator in the polymerization of styrene. Phthalimide functional pS 3a was then reacted with tributyltin hydride to remove the thermally labile alkoxyamine end-group from polymer $\mathbf{3 b}$. While the presence of the alkoxyamine end-group on $\mathrm{pS}$ surfactants was found to not affect the particle formation of ferromagnetic cobalt colloids, this step was performed to eliminate any concerns of alkoxyamine fragmentation during the thermolysis of thermolysis $\mathrm{Co}_{2} \mathrm{CO}_{8}$. Deprotection of the phthalimide group using hydrazine afforded a well-defined amine end-functional polystyrene $3 c\left(\mathrm{M}_{\mathrm{nSEC}}=\right.$ 4,$\left.950 ; \mathrm{M}_{\mathrm{w}} / \mathrm{M}_{\mathrm{n}}=1.09\right)$.

Phosphine oxide terminal polystyrene $4 b\left(P S-D O P O, M_{n \text { SEC }}=5,100 ; M_{w} / M_{n}=1.10\right.$ ) was synthesized using a similar strategy via the controlled polymerization of styrene using alkoxyamine 2 to afford 4a, followed by removal of the alkoxyamine chain end by treatment with tributyltin hydride. 


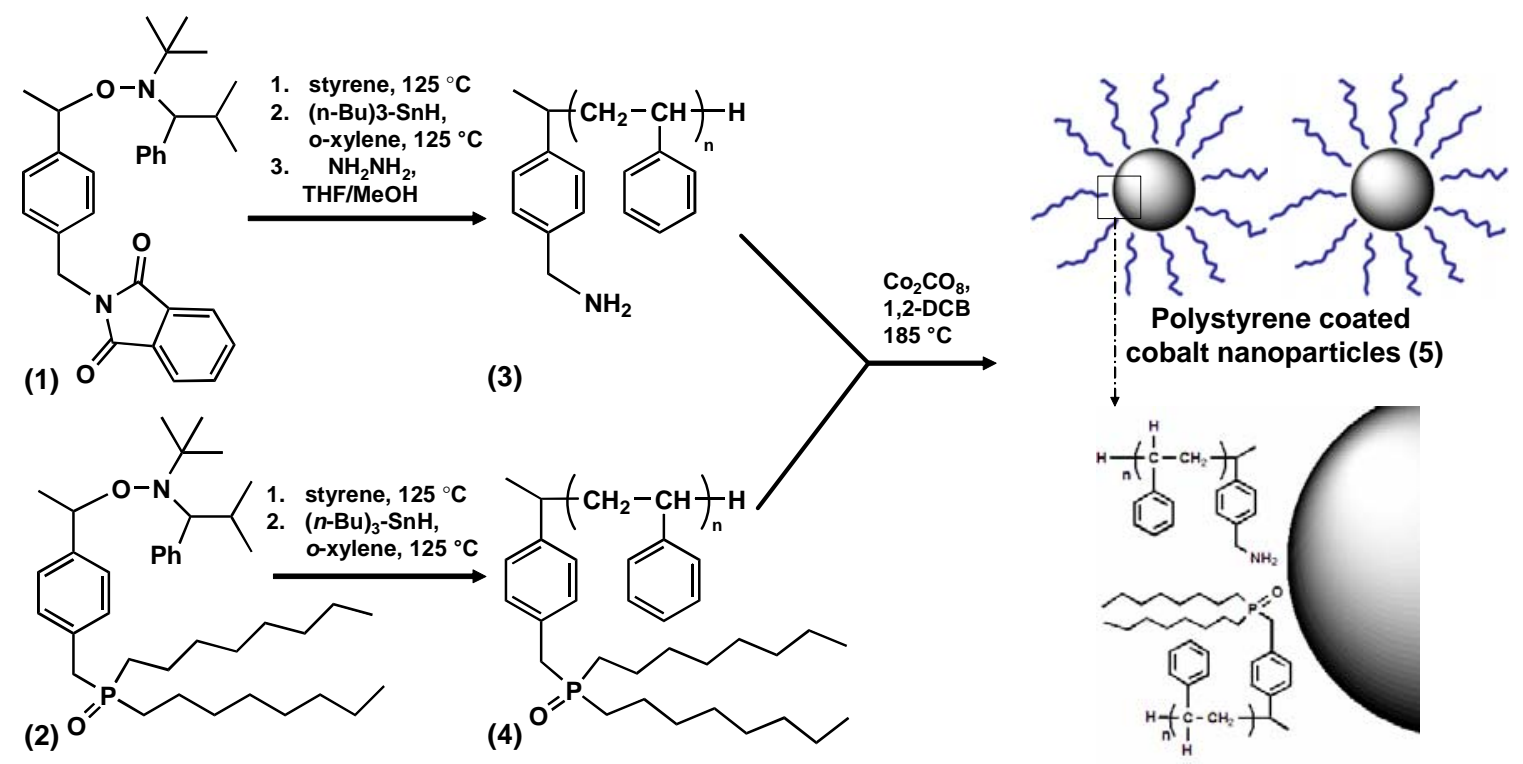

Scheme S-1. Methodology for preparation of polystyrene coated cobalt nanoparticles.

\section{Effect of molecular weight of end functional polymer surfactants.}

A systematic study varying the molecular weight of end-functional polymers was conducted where different pS surfactants, ranging from $M_{n} \sim 2000$ to $9000 \mathrm{~g} / \mathrm{mol}$ (Figure S-3), were evaluated for the preparation of ferromagnetic cobalt nanoparticles. It was found that a mixed surfactant system possessing amine and phosphine oxide groups with a $M_{n}=5000 \mathrm{~g} / \mathrm{mol}$ was optimal, resulting in well-defined ferromagnetic nanoparticles of uniform size and shape. In agreement with small molecule systems, ${ }^{5}$ it was observed that the use of only one end-functional polymer resulted in poorer control of particle size and morphology, in comparison to the mixed ligand systems. It was observed that variation of polymer surfactant molar mass resulted in broad particle size distributions and decreased uniformity of prepared nanoparticles (Figures S-4 and S5). When using a low molecular weight polymer surfactant system, $M_{n}=2000 \mathrm{~g} / \mathrm{mol}$, a particle size distribution of $15 \mathrm{~nm} \pm 2.5 \mathrm{~nm}$ for cobalt cores was observed. In addition, the TEM image indicates a tendency of particles to aggregate together during the process of sample preparation and drying. Conversely, a higher molecular weight polystyrene system, $\mathrm{M}_{\mathrm{n}}=8500 \mathrm{~g} / \mathrm{mol}$, resulted in smaller, more isolated particles with decreased chaining. The TEM analysis indicated a particle size distribution of $13 \mathrm{~nm} \pm 2.2 \mathrm{~nm}$ for cobalt cores. In each case, deviation from the $5,000 \mathrm{~g} / \mathrm{mol}$ system resulted in broader particle size distributions. 


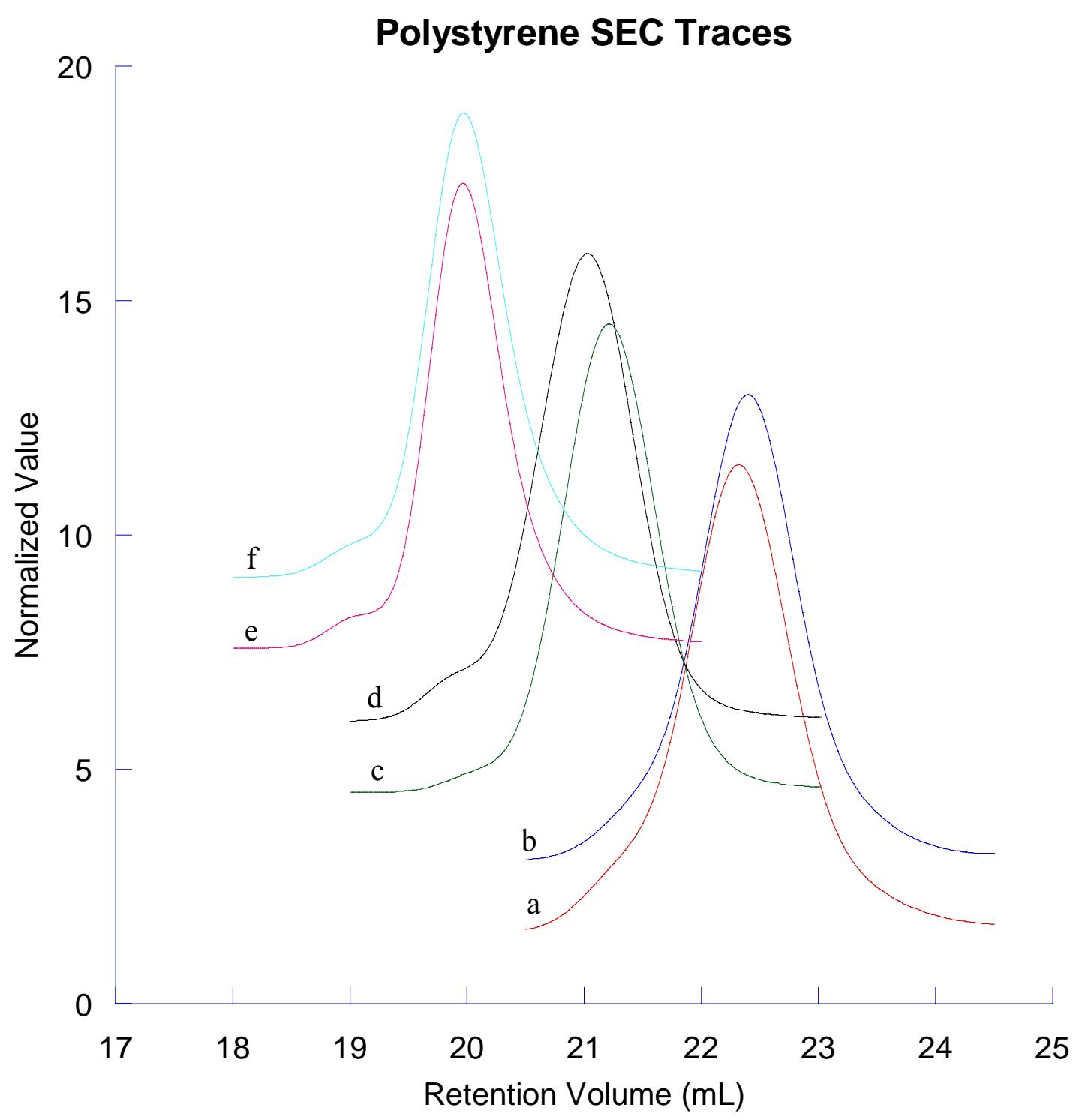

Figure S-3. SEC traces of end functional polystyrenes used in molecular weight study. In ascending order, a) Phthalimide-PS, $M_{n}=2400 \mathrm{~g} / \mathrm{mol}$, pdi 1.11; b) Dopo- $P S, M_{n}=2400$ $\mathrm{g} / \mathrm{mol}, 1.09$; c) Phthalimide-PS(3b), $M_{n}=4950 \mathrm{~g} / \mathrm{mol}$, pdi 1.09; d) Dopo-PS(4b), $M_{n}=5100$ $\mathrm{g} / \mathrm{mol}$, pdi 1.10 ; e) Phthalimide-PS, $M_{n}=8400 \mathrm{~g} / \mathrm{mol}$, pdi 1.08; f) Dopo- $P S, M_{n}=8300$ g/mol, pdi 1.10 .

In addition to deviation in particle size, colloidal stability was also observed to be affected by molecular weight. Stable colloidal dispersions were obtained for nanoparticles prepared from polymer surfactants of 5,000 and 8,500 g/mol, where colloids remained dispersed in organic media (e.g., toluene, methylene chloride, THF) over a period of several months. Conversely, colloidal dispersions prepared from either polymer surfactants of $2000 \mathrm{~g} / \mathrm{mol}$, or small molecule surfactant (oleic acid, TOPO, Figure S-6) ${ }^{5}$ flocculated out of solution within a 24 hour period (Figure S-7). 


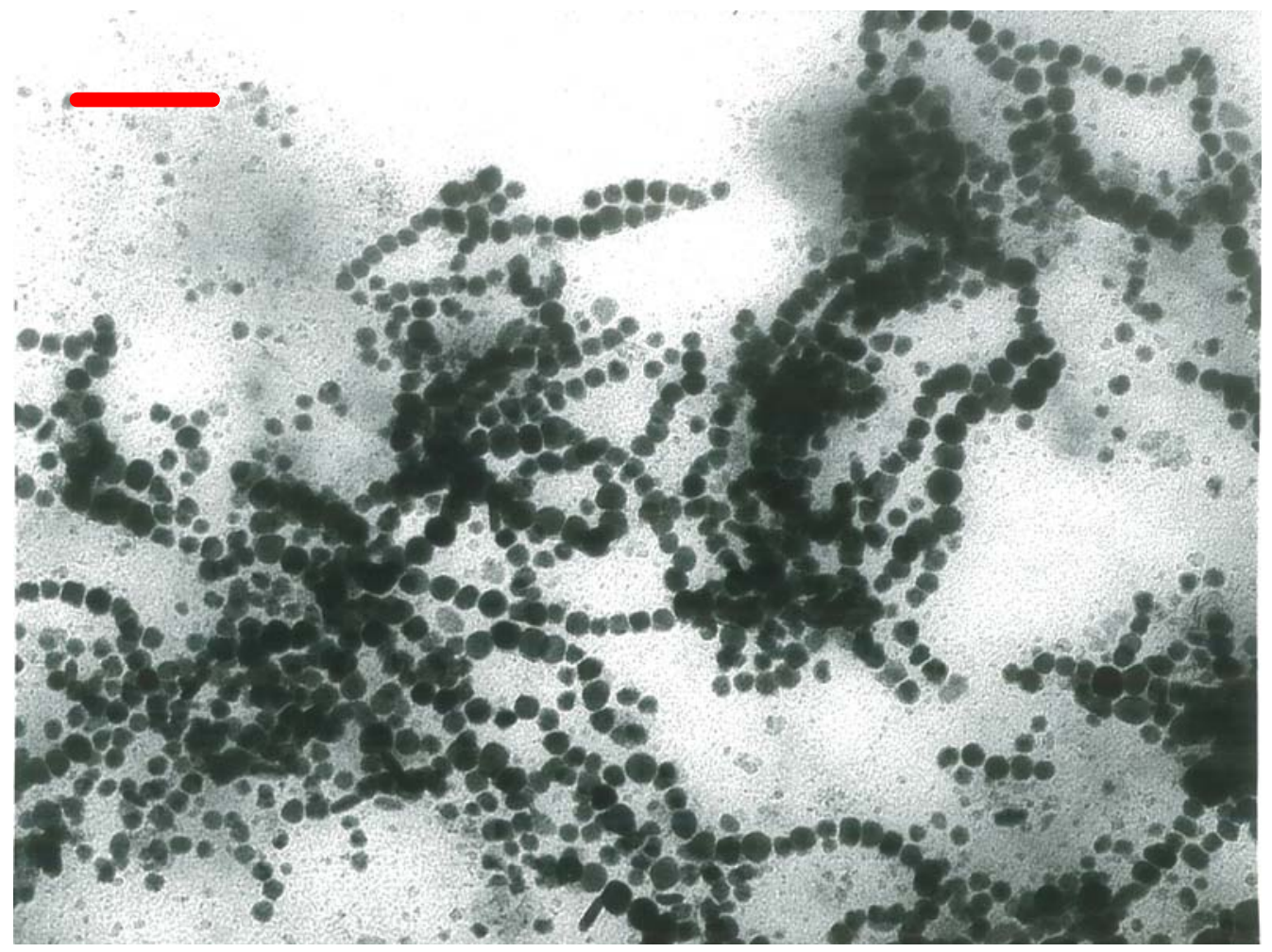

Figure S-4. TEM image of polystyrene coated cobalt nanoparticles (15 $\mathrm{nm} \pm 2.5 \mathrm{~nm})$ prepared from $2 k$ surfactant system. Bar $=100 \mathrm{~nm}$

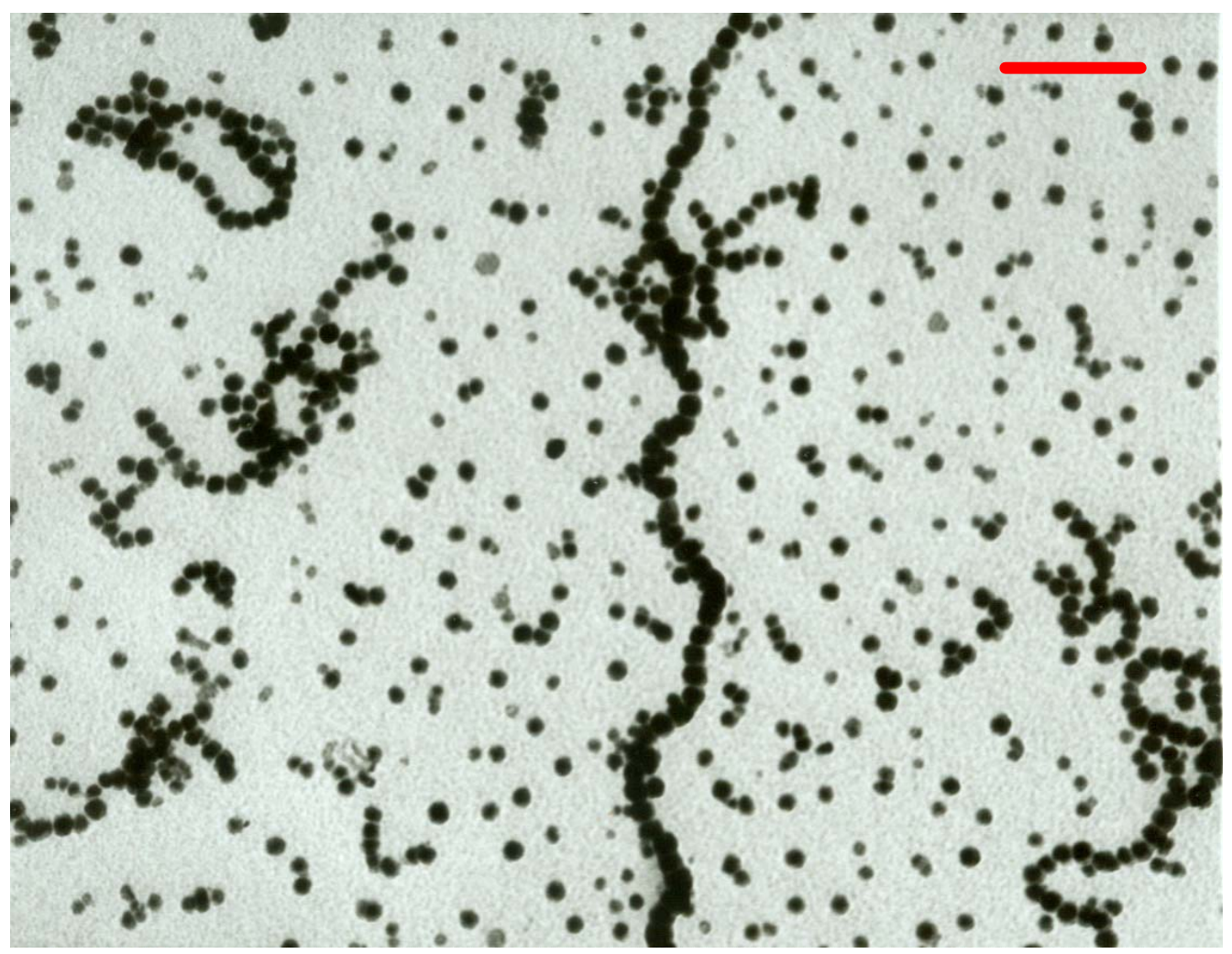

Figure S-5. TEM image of polystyrene coated cobalt nanoparticles (13 $\mathrm{nm} \pm 2.2$ nm) prepared from $8.5 \mathrm{k}$ surfactant system. Bar $=100 \mathrm{~nm}$ 


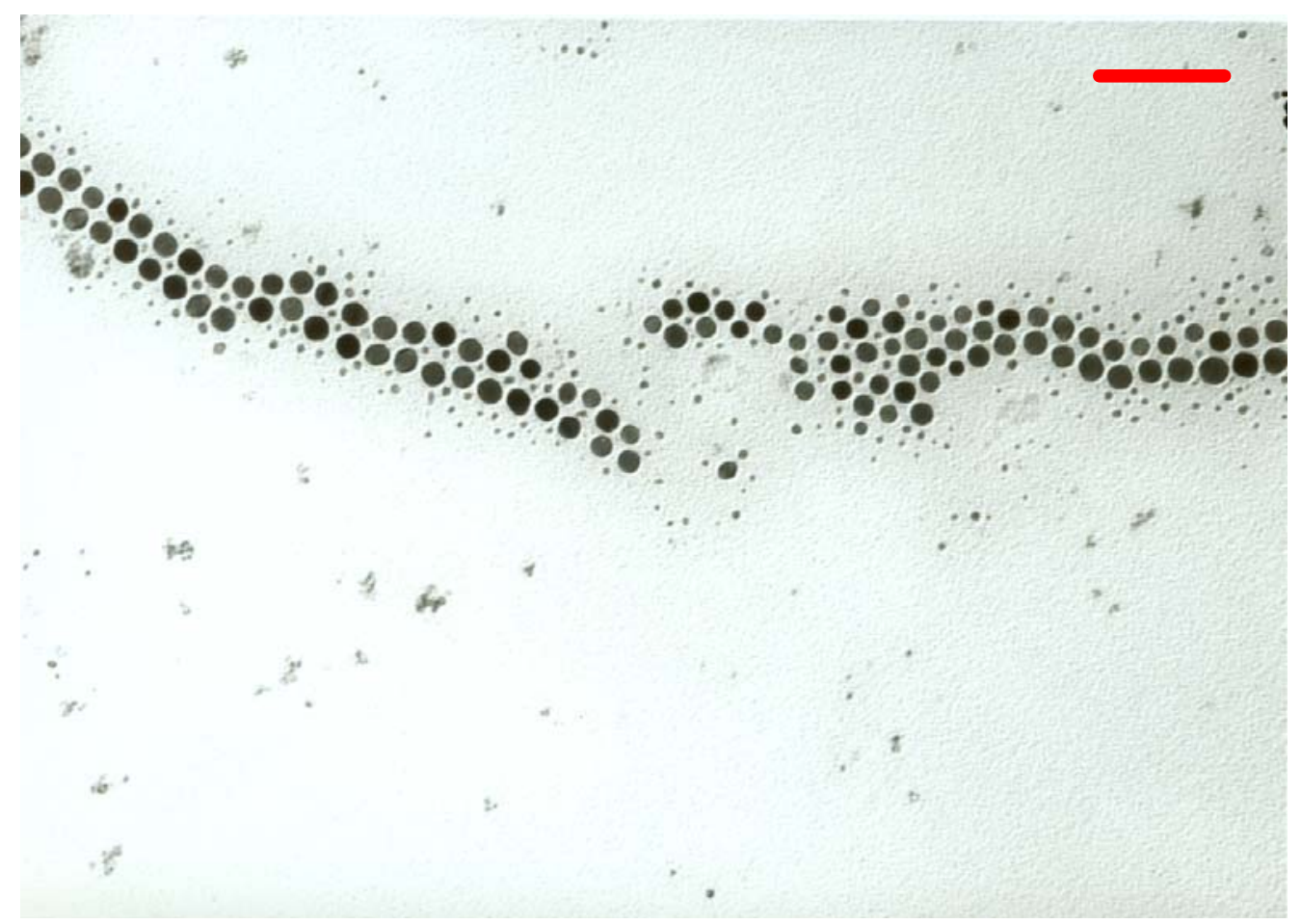

Figure S-6. TEM image of cobalt nanoparticles $(19.7 \pm 2.8 \mathrm{~nm})$ prepared from oleic acid and TOPO. Bar $=100 \mathrm{~nm}$

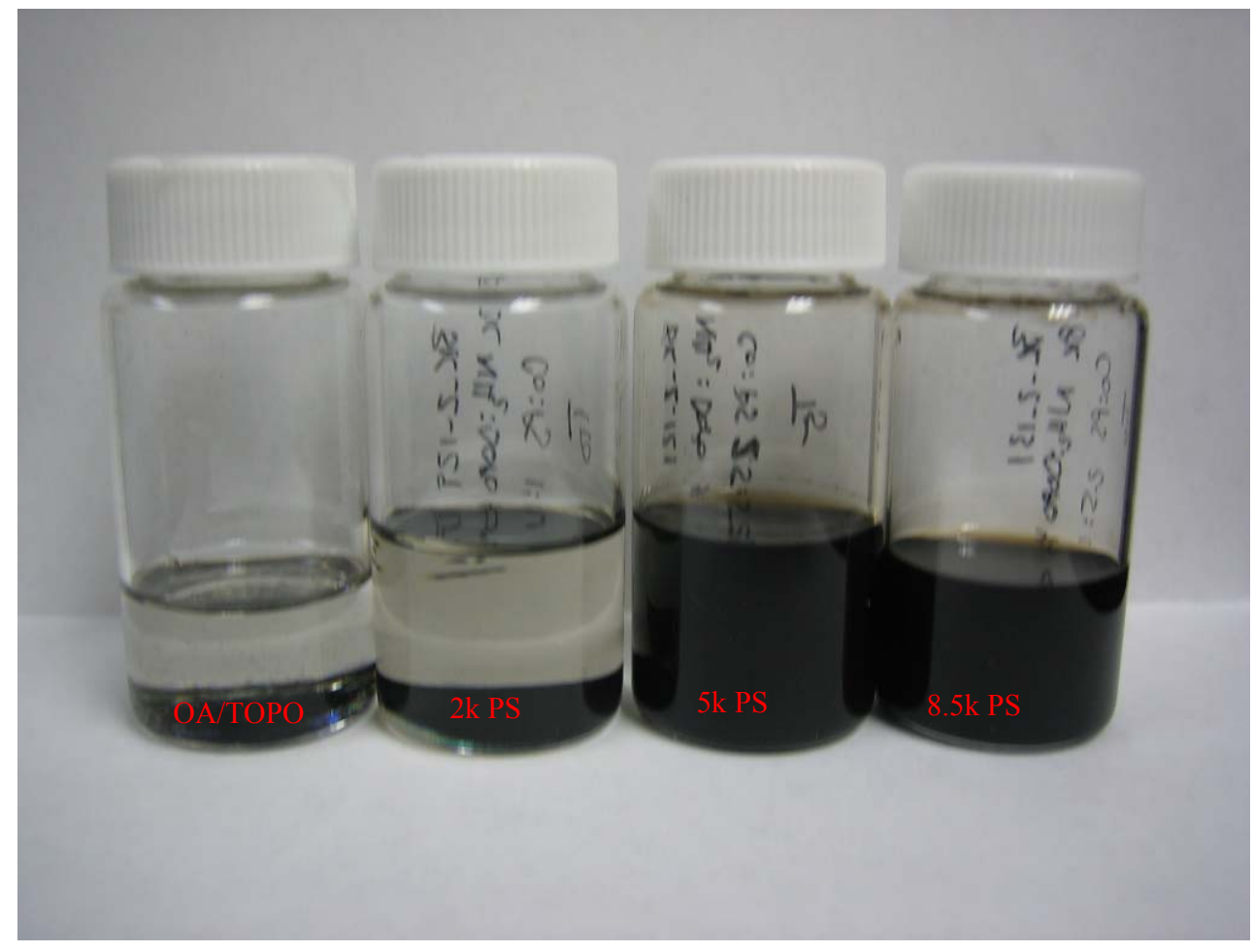

Figure S-7. Digital image of prepared cobalt nanoparticles from various surfactant systems. In order from left to right, OA/TOPO, $2 k P S, 5 K P S, 8.5 k P S$ 
Solid State Characterization of Nanocomposite Composition. The polymer coated nanoparticles crystalline phase was determined to be fcc by XRD (Figure S-8). The peaks determined experimentally correspond well with simulated XRD peaks for fcc cobalt nanoparticles previously reported. ${ }^{5}$ The observation of fec cobalt nanoparticles from this polymer surfactant system differs from the $\varepsilon$-phase cobalt nanoparticles typically seen from small molecule systems based aliphatic amines and TOPO. ${ }^{5}$ However, the observation of the fcc phase is in agreement with previous reports of cobalt nanoparticle preparation from polymer surfactant systems. ${ }^{6}$

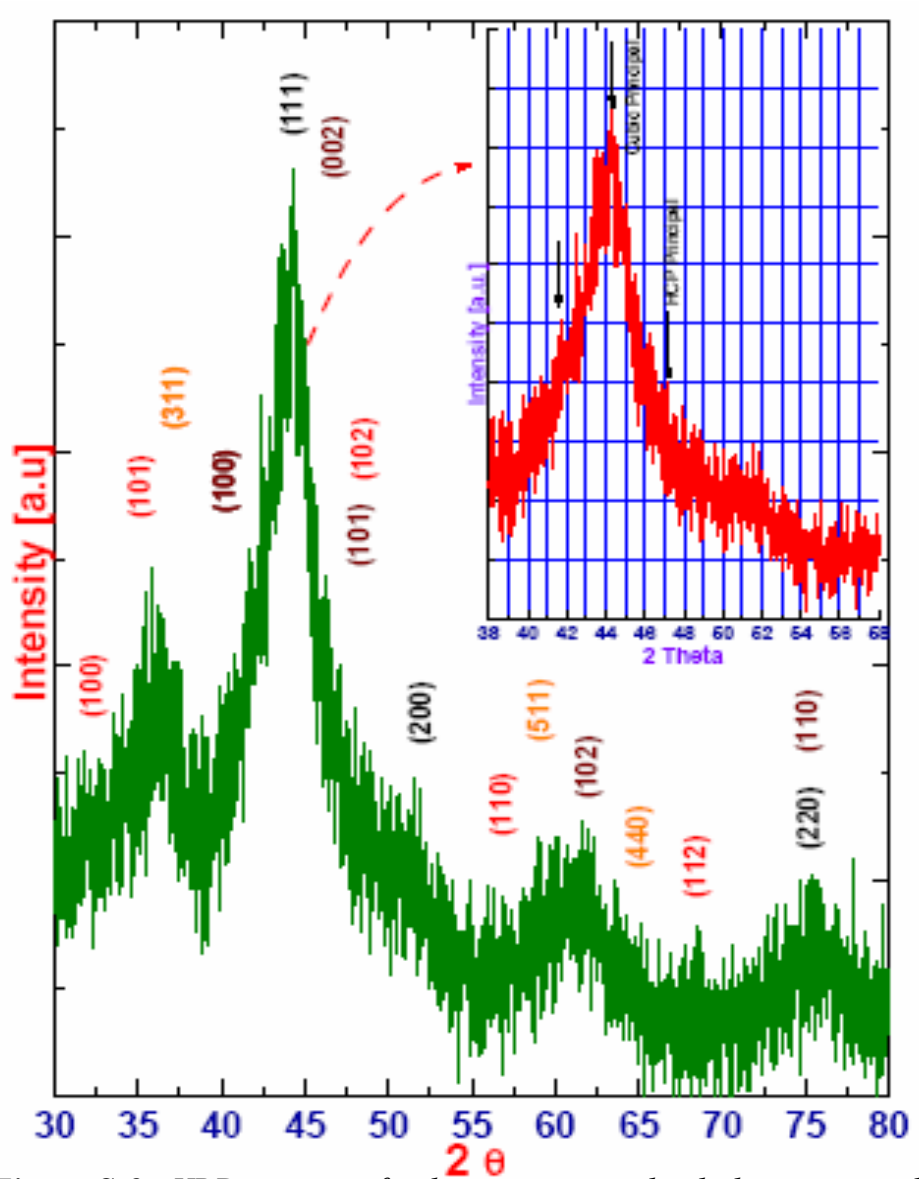

Figure S-8. XRD spectra of polystyrene coated cobalt nanoparticles indicating fcc phase. 

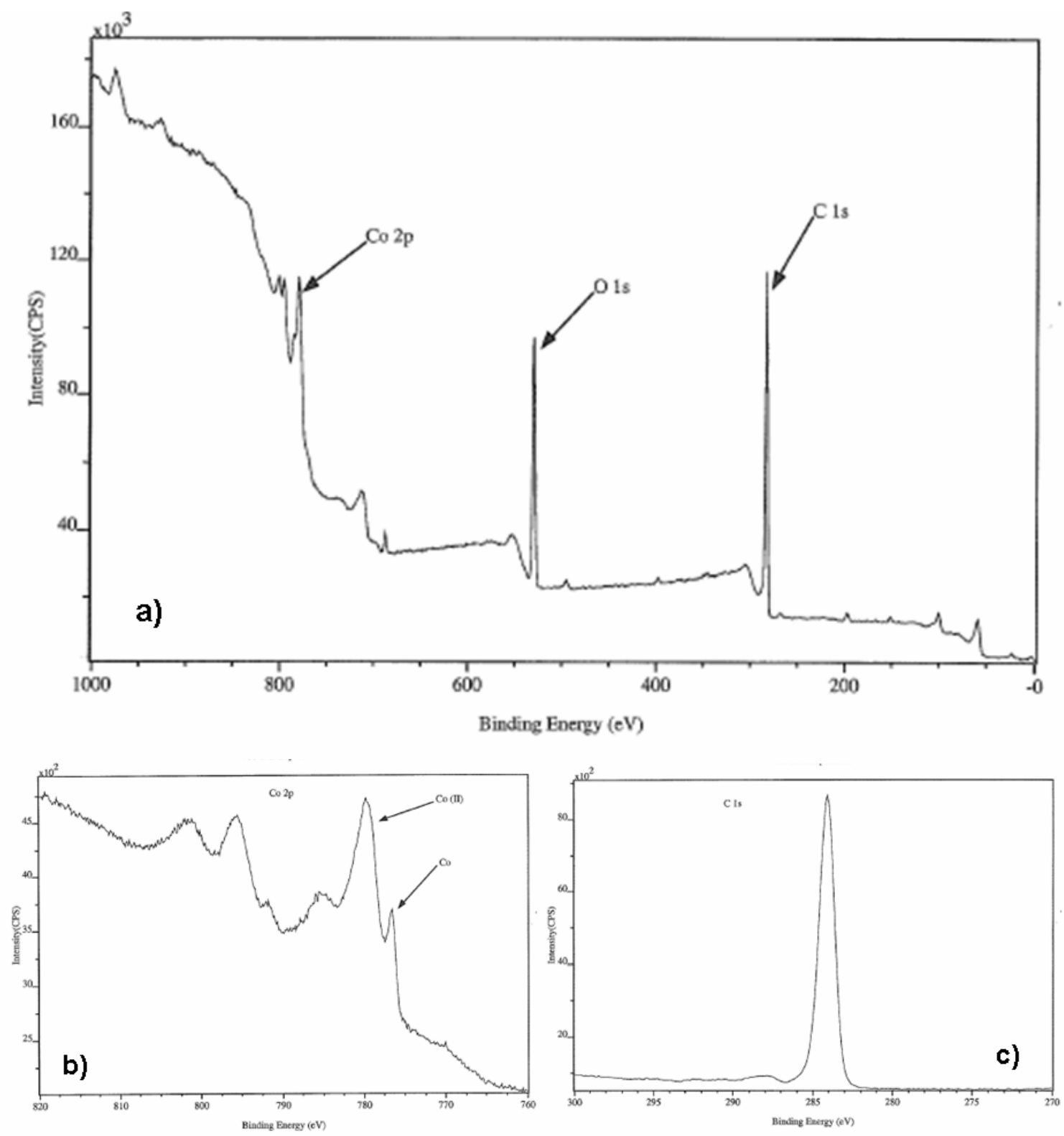

Figure S-9: (a) XPS spectrum of pS-coated ferromagnetic cobalt colloids (b) expanded spectrum of cobalt peaks (c) expanded spectrum of carbon peaks

XPS Measurements. The presence of both polystyrene and metallic cobalt was confirmed using XPS on powders of nanocomposite materials. Samples were "demagnetized" before analysis by treatment in a magnetic field to randomize the orientation of nanoparticle dipoles. Peaks at 284 $\mathrm{eV}$ and $288 \mathrm{eV}$ were assigned to $\mathrm{C} 1 \mathrm{~s}$ peaks present in polystyrene. XPS revealed the presence of oxygen $(535 \mathrm{eV})$, cobalt (II) $(780 \mathrm{eV})$ and cobalt $(0)(776 \mathrm{eV})$ species, which confirmed the formation of metallic cobalt and cobalt oxide (CoO). Due to the limited penetration depth of XPS ( $\sim$ few nanometers), the $\mathrm{x}$-rays are able to more efficiently expel electrons from the $\mathrm{pS}$ and $\mathrm{CoO}$ shells, and to a lesser degree from the cobalt metal core. Thus, the content of the CoO phase is inflated in the XPS spectrum, but nevertheless confirms the formation of a pS-cobalt nanocomposite material, in agreement with TEM, AFM and XRD data. 
Magnetic measurements of polystyrene coated cobalt nanoparticles. The magnetic properties of precipitated polystyrene coated cobalt nanoparticles were tested using VSM measurements. The polymer coated cobalt nanoparticle powder $\left(\mathrm{M}_{\mathrm{s}}=38 \mathrm{emu} / \mathrm{g}\right)$ exhibited ferromagnetic behavior at room temperature $(300 \mathrm{~K})$ with a coercivity $\left(\mathrm{H}_{\mathrm{c}}\right)$ of $110 \mathrm{Oe}$, while measurement at

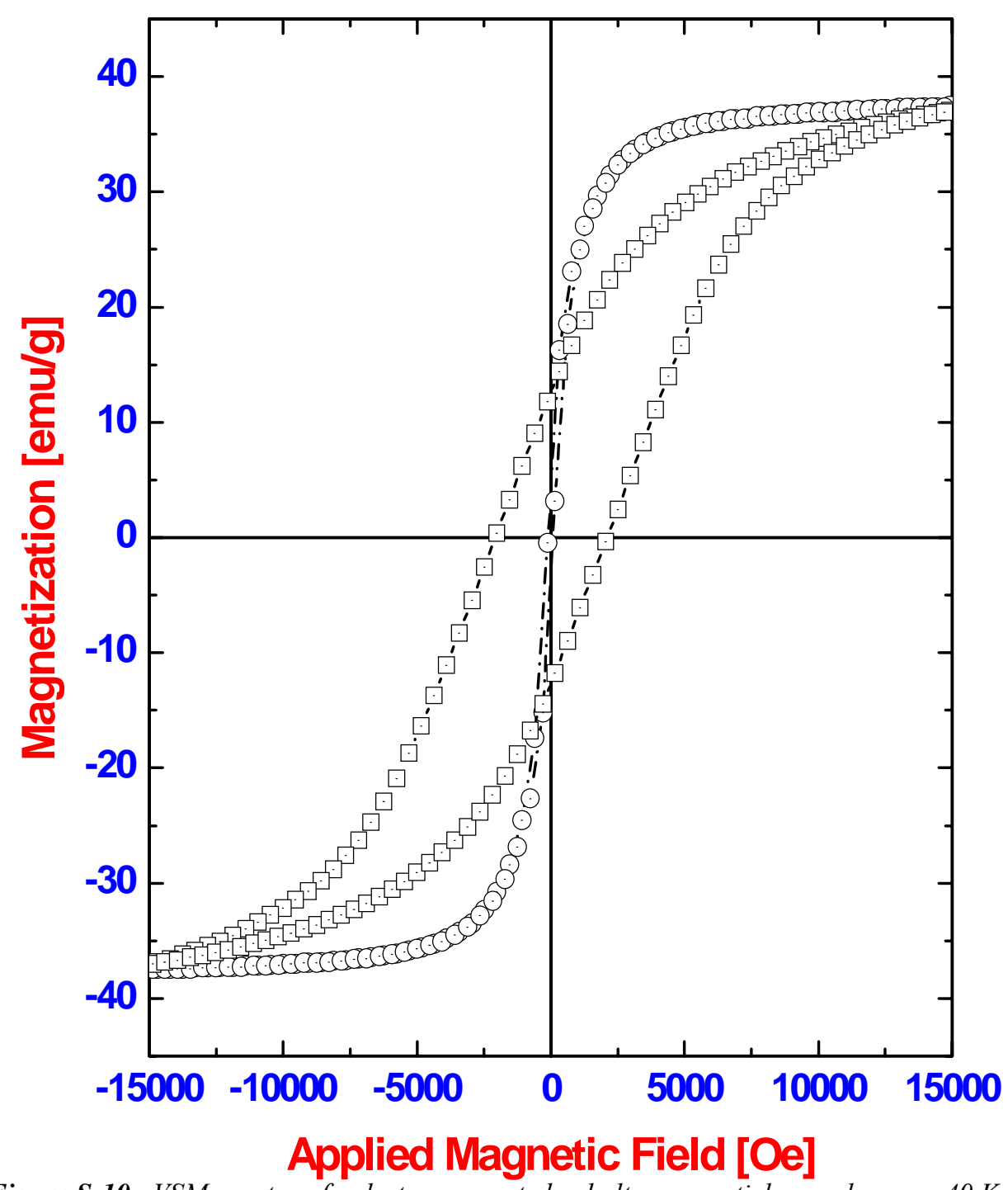

Figure S-10. VSM spectra of polystyrene coated cobalt nanoparticle powder. $\quad$ - $40 \mathrm{~K}$, ०$300 \mathrm{~K}$.

low temperature $(40 \mathrm{~K})$ showed an increased coercivity of 2000 Oe (Figure S-10). Thin films of polystyrene coated cobalt nanoparticles were prepared by dispersing 5 in tetrahydrofuran followed by drop casting onto polyethyleneteraphthalate (PET) in the presence of a weak magnetic field $(0.1 \mathrm{~T})$. The thin film was then subjected to VSM measurement and the results indicated an increase in room temperature coercivity from 110 Oe to 340 Oe due to magnetic alignment during the film casting process (Figure S-11). 


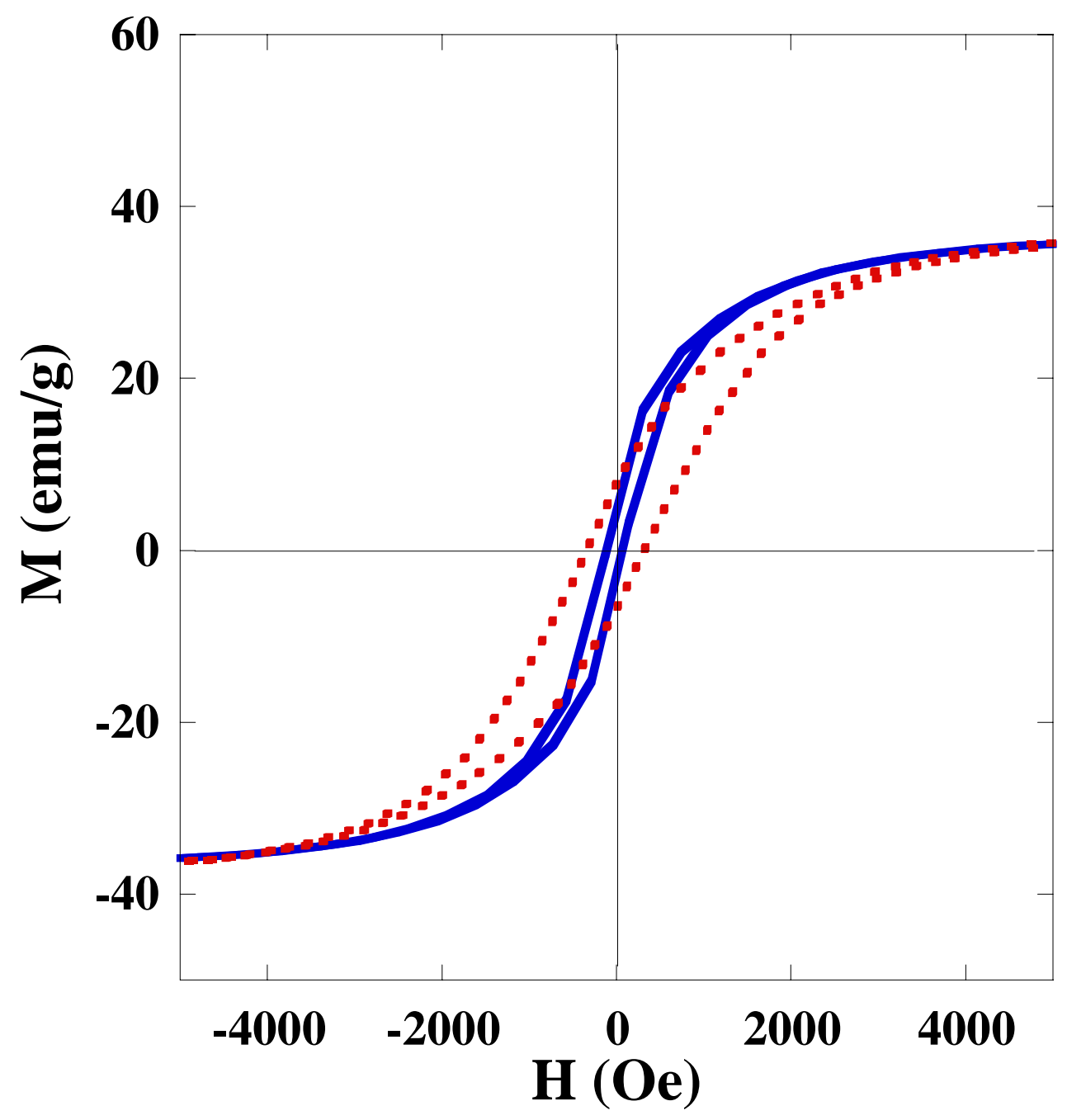

Figure S-11. VSM spectra of polystyrene coated cobalt nanoparticle powder. Solid Line - 300 K, no alignment; Dotted Line - 300 K, aligned. 


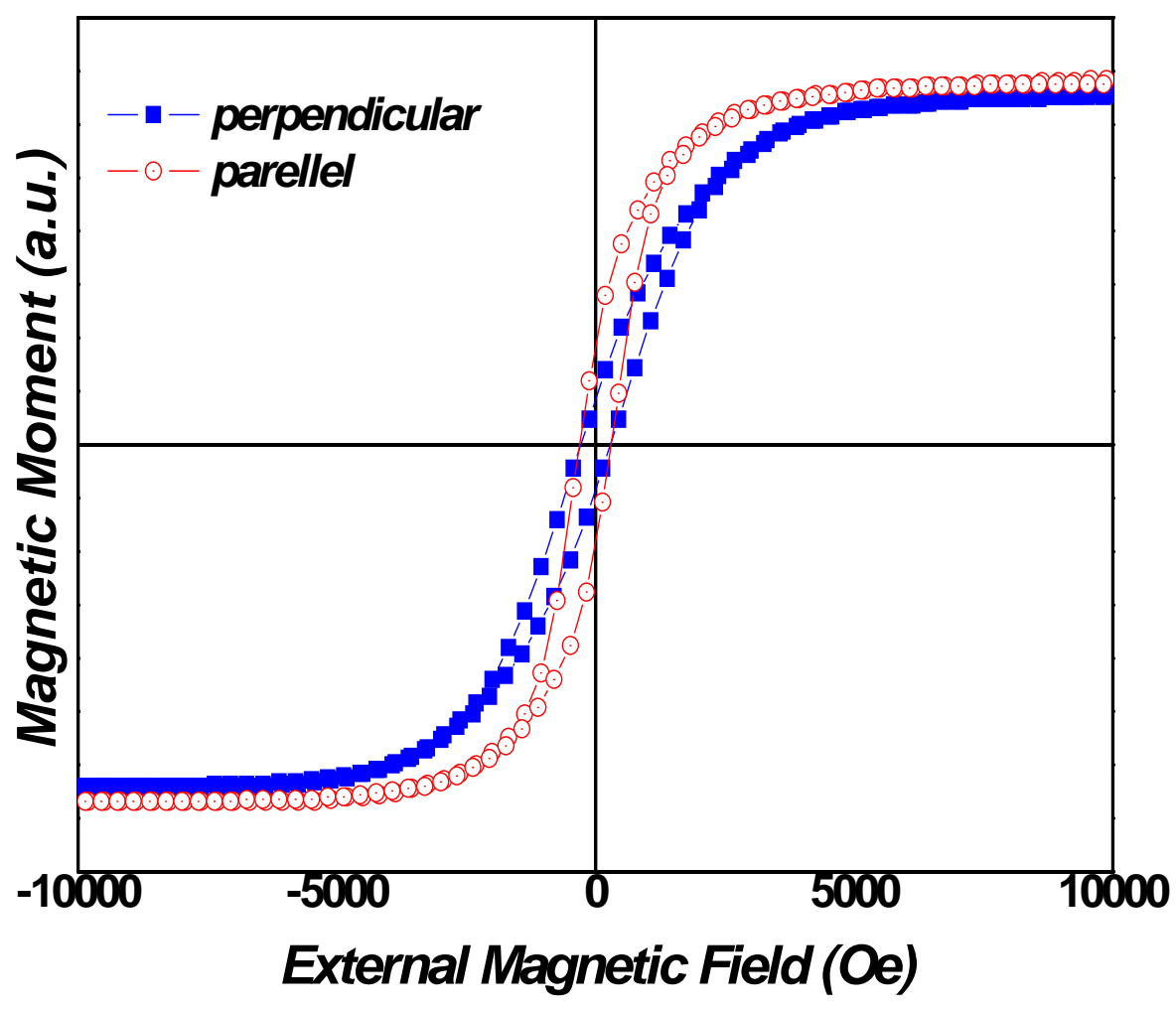

Figure S-12. VSM spectra of polystyrene coated cobalt nanoparticle powder at $300 \mathrm{~K}$ after alignment. Circles - parallel to alignment direction;; Dotted Line-perpendicular to alignment direction.

Owing to the brittlenetss of polystyrene coated cobalt nanoparticles, films were cast onto polyethyleneteraphthalate (PET) substrates and VSM was performed from $40 \mathrm{~K}$ to $300 \mathrm{~K}$ temperature ranges (Fig. S-12). As seen in the $\mathrm{M}$ vs. $\mathrm{H}$ plots, measurements parallel to the alignment axis generate standard hysteresis loops. Measurements perpendicular to the aligned film exhibit slightly different behavior, but possess comparable $\mathrm{M}_{\mathrm{s}}$ and $\mathrm{H}_{\mathrm{c}}$ values. When the applied magnetic field is parallel to the PET substrate, the remanence $\left(\mathrm{M}_{\mathrm{r}}\right)$ to saturation magnetization $\left(\mathrm{M}_{\mathrm{s}}\right)$ ratio; $\mathrm{M}_{\mathrm{r}} / \mathrm{M}_{\mathrm{s}}$ is 0.27 . The hysteresis loop is squarer than that obtained perpendicular direction. When the applied magnetic field is perpendicular to the PET substrate, the remanence to saturation magnetization rtio is 0.12 . The hysteresis loop is smoother. This change is attributed to the magnetic shape anisotropy for polystyrene coated cobalt nanoparticles 
onto polyethyleneteraphthalate (PET) substrate. However, the differences of the magnetic hysteresis are weak, because these measurements were performed using thick films $(\sim 100 \mathrm{~nm})$ of the nanoparticles. Therefore, the shape anisotropy behavior of polystyrene coated Co aligned chain is diminished because the total demagnetization factors of thick films is lower.

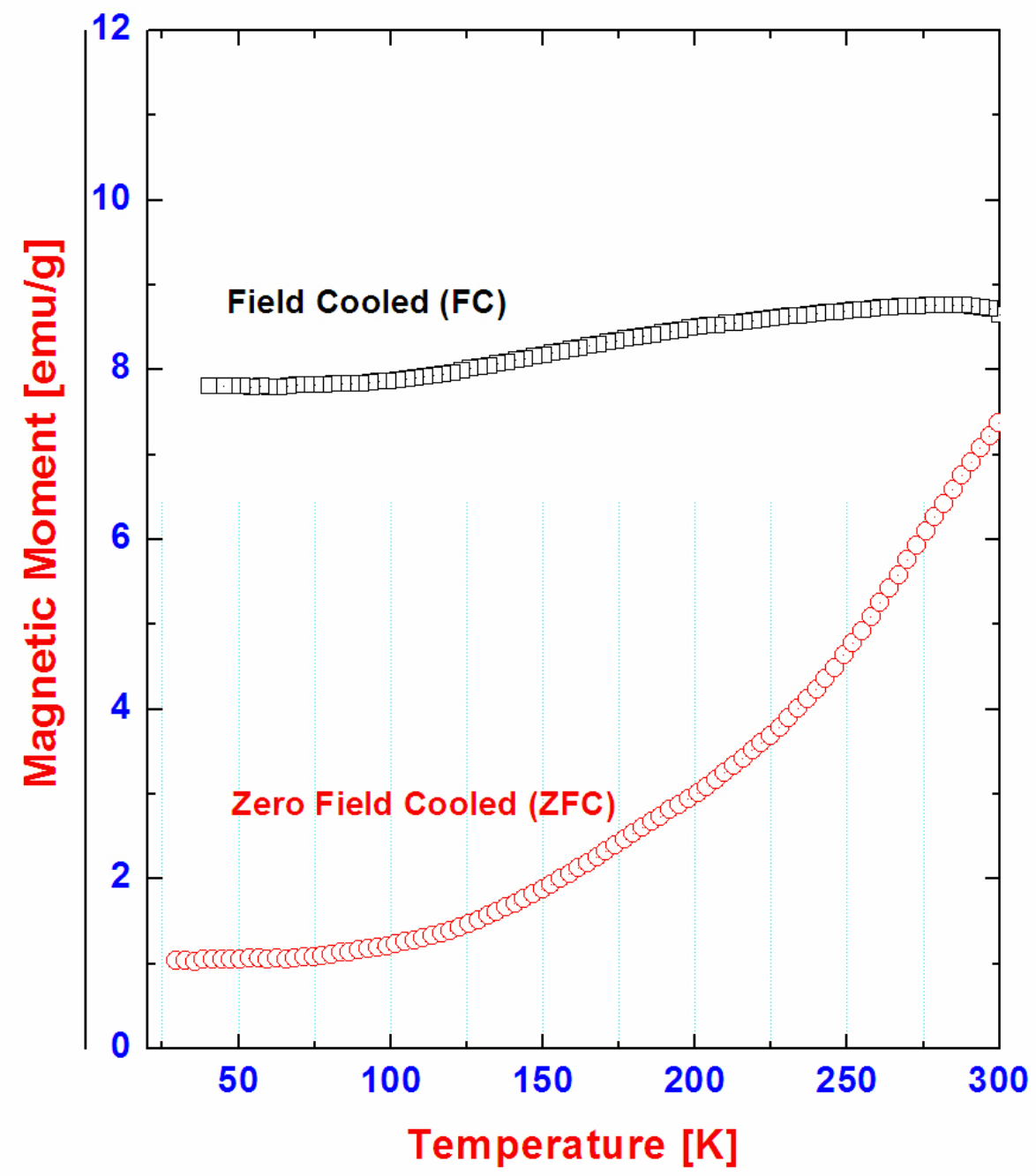

Figure S-13. Zero field cooled (ZFC) and field cooled (FC) magnetic measurements of PS-cobalt nanoparticles with f.c.c. cobalt colloids, with particle size $=15 \pm 1.5 \mathrm{~nm})$ in 100 Oe field.

The $\mathrm{ZFC} / \mathrm{FC}$ measurements indicated no blocking temperature at or below room temperature, further indicating that the polymer coated metallic nanoparticles are ferromagnetic at room temperature (Figure S-13). The temperature dependent magnetic measurements were conducted in a weak applied field (100 Oe), which induces magnetic moments that are significantly lower than the $M_{s}$ values at 10,000 Oe, however, the use of weak applied fields is necessary to evaluate 
the temperature dependence of the magnetization, as the use of stronger fields would align all spins even at lower temperatures.

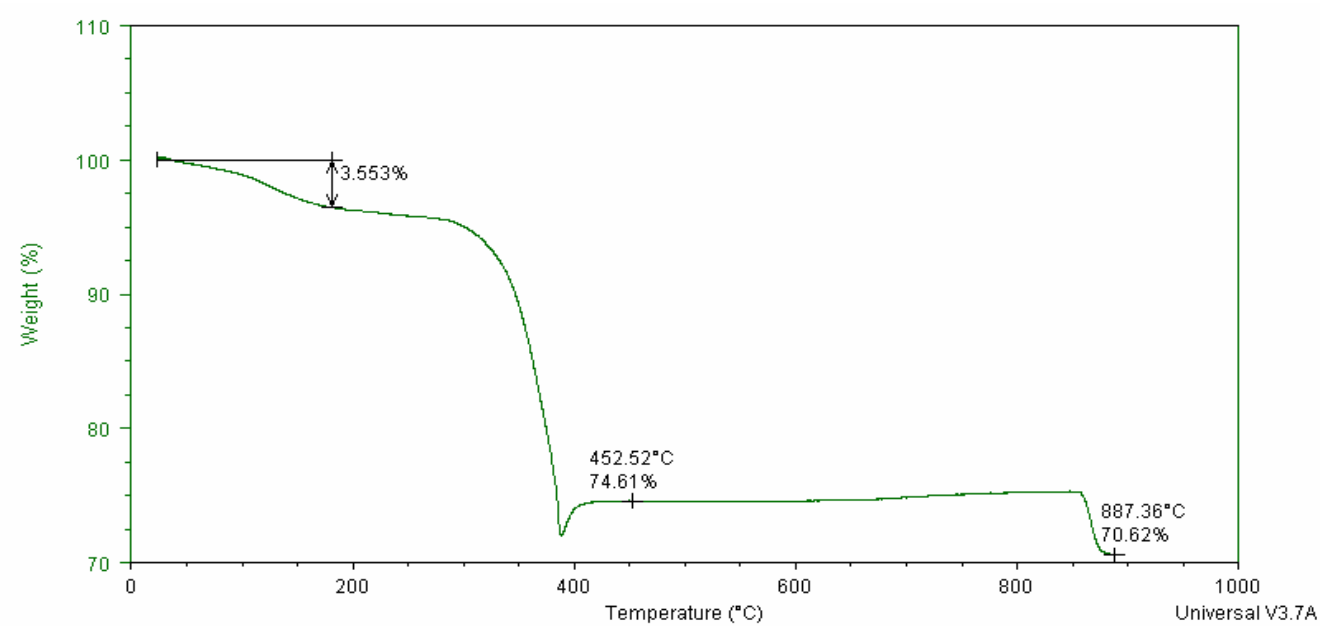

Fiqure S-14. TGA graph of polystyrene coated cobalt

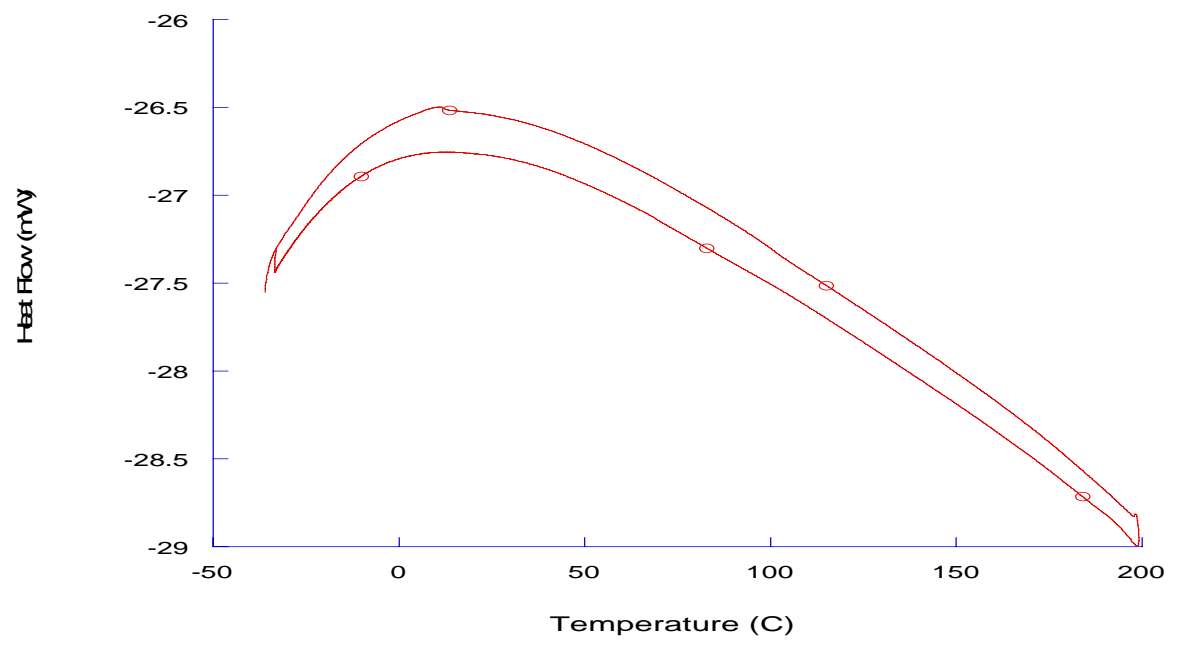

Fiaure S-15 DSC trace of nolvsturene conated cohalt

Characterization of polystyrene shell. Interrogation of the polymer shell surrounding the cobalt nanoparticle core was obtained via TGA and DSC measurements. The amount of polymer incorporated in the nanoparticle formation reaction was determined to be approximately $20 \%$ of the total mass of nanoparticle as indicated by the loss of mass between $300-400^{\circ} \mathrm{C}$ which corresponds to the degradation and loss of the polymer shell (Figure S-14). The loss of mass at approximately $100^{\circ} \mathrm{C}$ was attributed to residual solvent. The increase seen in the curve at approximately $380^{\circ} \mathrm{C}$ was due to an overshoot attributed to the small sample size. The slight increase in the curve from $600^{\circ} \mathrm{C}$ was attributed to oxidation of the sample during heating. According to DSC trace no significant $\mathrm{T}_{\mathrm{g}}$ could be detected from the measurement, likely due to the low percentage of polymer incorporated into the shell (indicated by TGA) and small sample size (Figure S-15). 


\section{Additional AFM/MFM images of PS-Cobalt Nanoparticle chains}

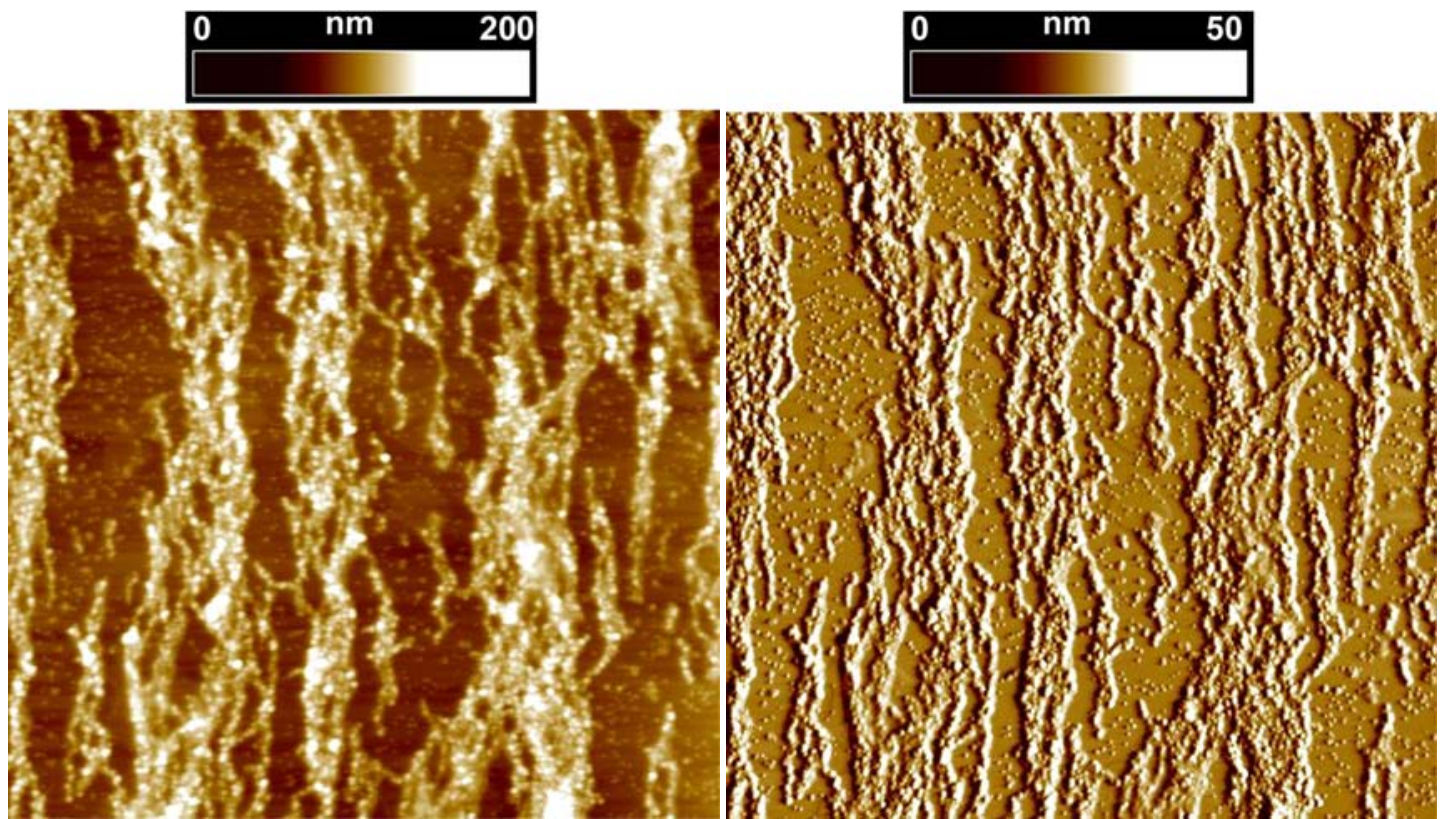

Figure S-16. AFM topography (Left) and amplitude (Right) images (size $10 \times 10 \mu \mathrm{m}^{2}$ ) of pS-cobalt nanoparticles cast onto carbon-coated mica in the presence of external magnetic field.

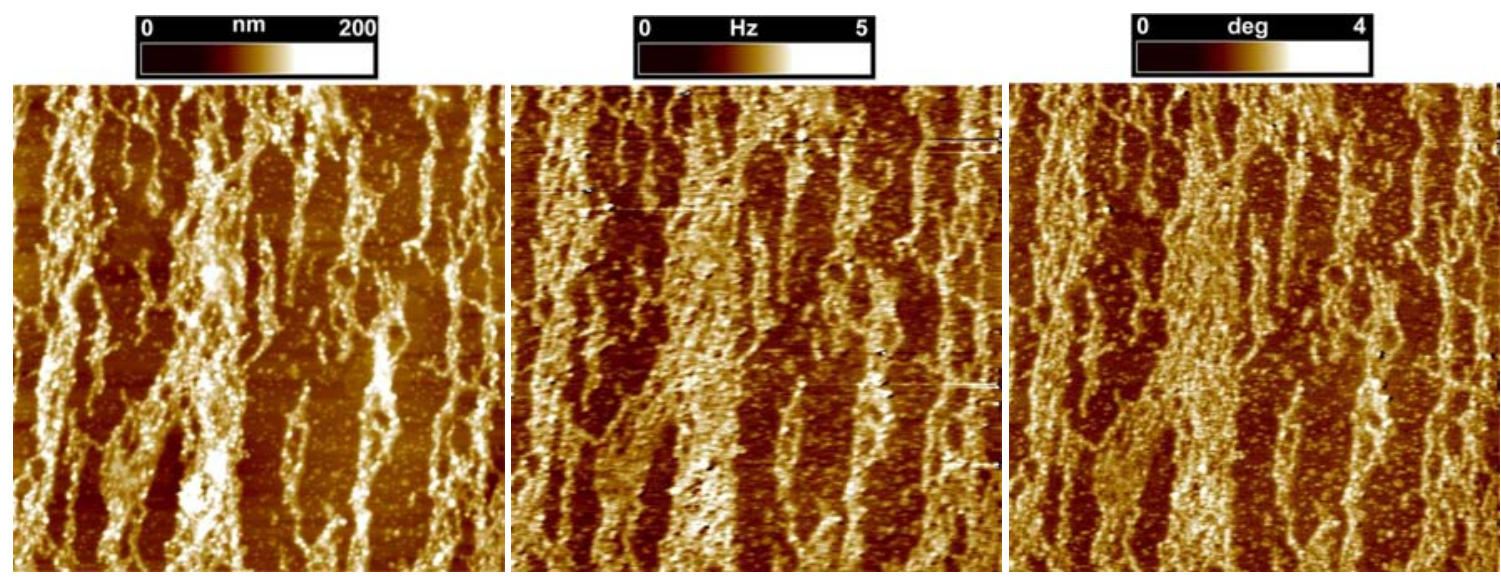

Figure S-17. Topography and MFM images (size $10 \times 10 \mu \mathrm{m}^{2}$ ) of pS-cobalt nanoparticles cast onto carbon-coated mica in the presence of external magnetic field. Left: AFM, height; middle: MFM, frequency; right: MFM, phase.

MFM images represent the phase or frequency shift induced by the tip-sample force in the oscillating cantilever scanned at constant height above the previously recorded topographic profile. For tip-sample forces perpendicular to the surface, the phase or frequency shift of the cantilever is a function of the gradient of tip-sample force (see, e.g. D. Sarid, Scanning Force Microscopy", 1994, Oxford University Press, New York, Oxford), and the brighter regions correspond to weaker attraction (or stronger repulsion). Reversal of tip magnetization results in contrast reversal in MFM images. The absence of reversal indicates that the net tip sample force 
was dominated by the component which was neither repulsive nor attractive. Such a situation would correspond to the sample magnetization dominated by the component parallel to the surface.

VI. Preparation of binary assemblies of pS-cobalt nanoparticles and $\mathrm{SiO}_{2}$ colloids. Silica particles were prepared according to reported methods. ${ }^{7}$ The silica particles prepared had a diameter of $172 \mathrm{~nm} \pm 22 \mathrm{~nm}$ (Figure S-18). Functionalization of the colloid periphery with methacrylate or stearyl functionality was obtained following reported literature. ${ }^{8,9}$ Blending experiments were carried out by combining polystyrene coated cobalt nanoparticles with silica particles dispersed in toluene in a 4:1 ratio by weight. From the blended dispersion, a drop of the solution was used to prepare the TEM sample via methods described earlier, resulting in the formation of assemblies of $\mathrm{SiO}_{2}$ and polystyrene coated colloid chains. The morphology of the assembled structure was found to be independent of the surface functionality of the $\mathrm{SiO}_{2}$ colloids. While the mechanism of this assembly process is yet to be determined, the result suggests the interstitial voids between $\mathrm{SiO}_{2}$ colloids offer sufficient unoccupied volume for 1-D chains to organize and meander around the much larger $\mathrm{SiO}_{2}$ inclusion. (Figure $\mathrm{S}-19$ ). In a series of control experiments using both oleic acid/TOPO capped superparamagnetic and ferromagnetic cobalt nanoparticles, blends with $\mathrm{SiO}_{2}$ colloids were performed identically, as for the PS-Co nanoparticles. In both cases, cobalt nanoparicles did not form 1-D assemblies and aggregated within the interstitial voids between $\mathrm{SiO}_{2}$ particles (Figure S-20). This lack of mechanical integrity between small molecule surfactant capped cobalt nanoparticles indicates that for PS-Co assemblies, interdigitation of glassy polymers is able to hold together nanoparticle chains in these blending experiments.

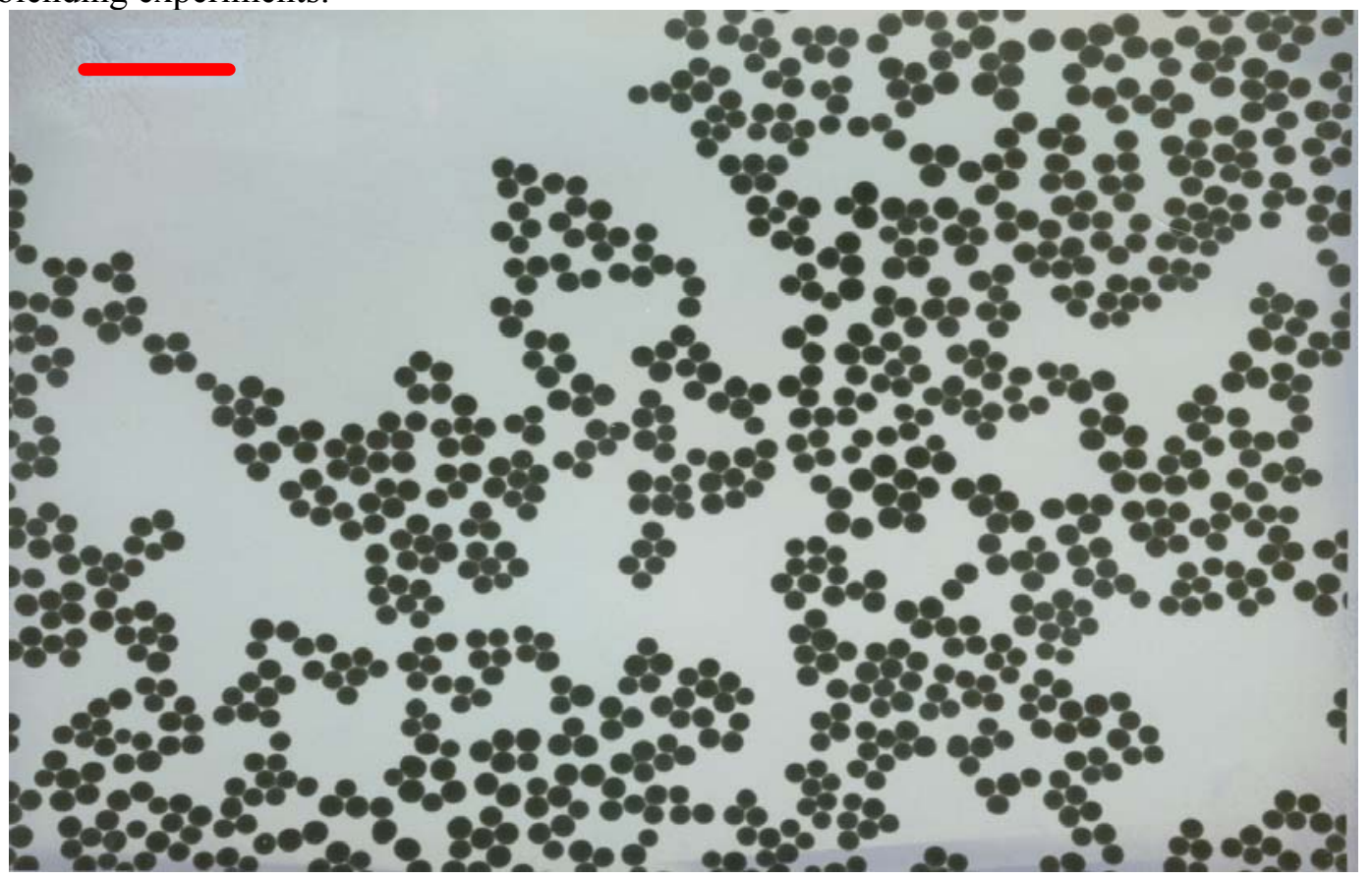

Figure S-18. TEM image of $\mathrm{SiO}_{2}$ particles $(172 \mathrm{~nm} \pm 22 \mathrm{~nm})$ prepared from the Stöber process. Bar $=1 \mu \mathrm{m}$ 


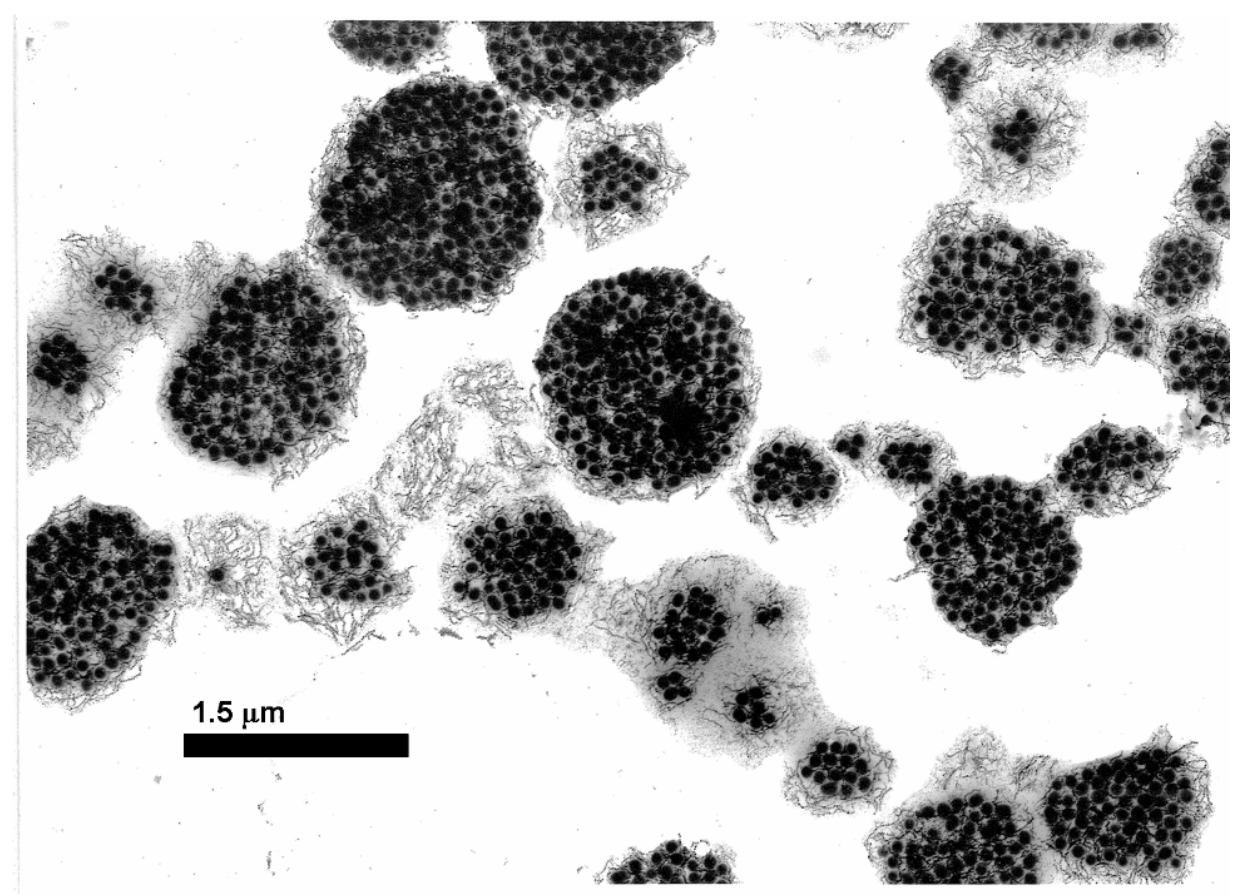

Figure S-19. TEM image of $p S$-cobalt nanoparticles $(d=20 \mathrm{~nm})$ blended with $\mathrm{SiO}_{2}$ particles $(172 \mathrm{~nm} \pm$ $22 \mathrm{~nm})(4: 1 \mathrm{wt}$ ratio) in toluene (1-wt\% solids) and cast onto carbon coated TEM grid.

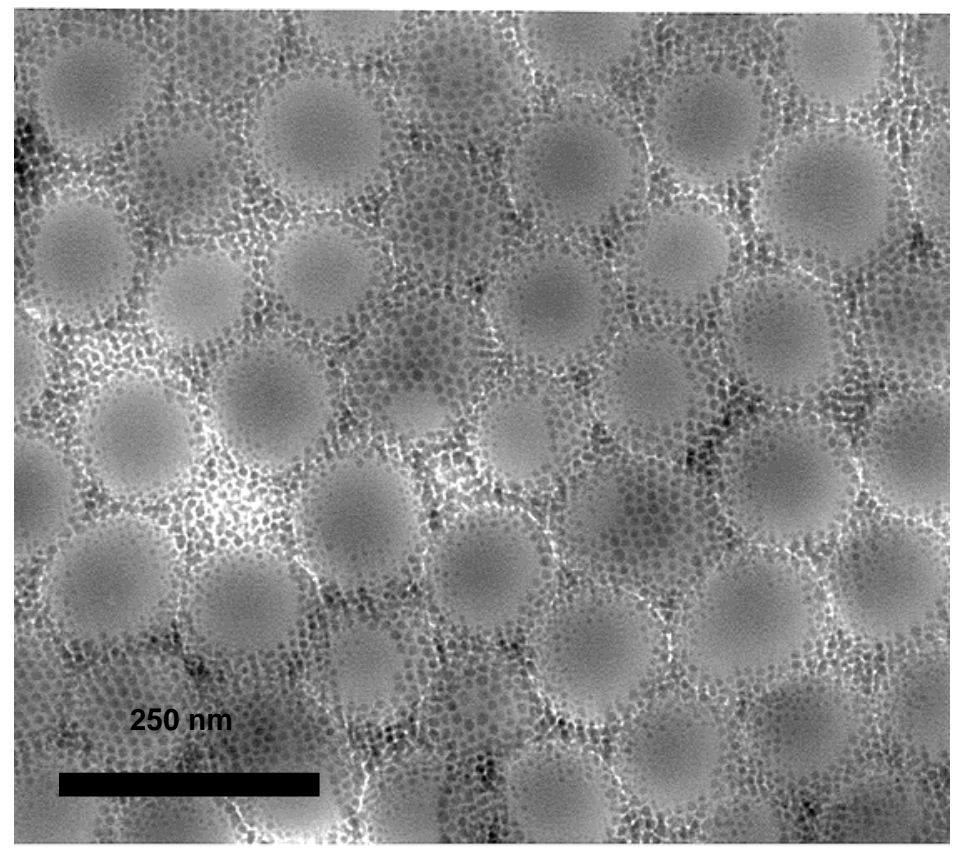

Figure S-20. TEM image of oleic acid/TOPO capped cobalt nanoparticles $(d=12 \mathrm{~nm})$ blended with methacrylate coated $\mathrm{SiO}_{2}$ particles $(172 \mathrm{~nm} \pm 22 \mathrm{~nm})$ (4:1 wt ratio) in toluene (1-wt\% solids) and cast onto carbon coated TEM grid. 


\section{References in Supporting Information:}

1. Benoit, D.; Chaplinski, V.; Braslau, R.; Hawker, C. J. J. Am. Chem. Soc. 1999, 121, 3904-3920.

2. a)Williams, R. H.; Hamilton, L. A. J. Am. Chem. Soc. 1952, 74, 5418-5420. b) Skaff, H.; Firat Illker, M.; Bryan Coughlin, E.; Emrick, T. J. Am. Chem. Soc. 2002, 124, 5729-5733.

3. Puntes, V. F.; Gorostiza, P.; Aruguete, D. M.; Bastus, N. G.; Alivisatos, P. Nature Mater. 2004, 3, 263-268

4. Harrowven, D. C.; Guy, I. L. Chem. Commun. 2004, 17, 1968-1969

5. Puntes, V. F.; Zanchet, D.; Erdonmez, C. K.; Alivisatos, A. P. J. Am. Chem. Soc. 2002, 124, 12874-12880.

6. Thomas, J. R. J. Appl. Phys. 1965, 37, 2914-2915.

7. Stöber, W.; Fink, A. J. Colloid Interface Sci. 1968, 26, 62-69

8. Philipse, A. P.; Vrij, A. J. Colloid Interface Sci. 1989, 128(1), 121-136

9. Van Helden, A.K.; Jansen, J.W.; Vrij, A. J. Colloid Interface Sci. 1981, 2, 354368.

\section{Additional References to Manuscript:}

Magnetic Assembly Ref\#1:

a) Grzybowski, B. A.; Stone, H. A.; Whitesides, G. M. Nature 2000, 405, 1033-1036. (b) Tripp, S. L.; Pusztay, S. V.; Ribbe, A. E.; Wei, A. J. Am. Chem. Soc. 2002, 124, 7914. (c) Germain, V.; Pileni, M.-P. Adv. Mater. 2005, 17, (11), 1424-1429. (d) Cheng, G.; Romero, D.; Fraser, G.T.; Hight Walker, A. Langmuir 2005, 21, 12055-12059.

Dipolar Associations of Ferromagnetic Colloids Ref \#2:

(a) Bao, Y.; Beerman, M.; Krishnan, K. M. J. Mag. Mag. Mater. 2003, 266, 1245-1249.

Surface Initiated Polymerization from Magnetic Nanoparticles Ref \#3:

(a) Marutani, E.; Yamamoto, S.; Ninjbadgar, T.; Tsujii, Y.; Fukuda, T.; Takano, M. Polymer 2004, 45, (7), 2231-2235. b) Wang, Y.; Teng, X.; Wang, J.-S.; Yang, H. NanoLett. 2003, $3,(6), 789-793$.

Polymers and Block Copolymers as Surfactants and Templates Ref \#4

(a) Sohn, B.H.; Cohen, R.E.; Chem. Mater. 1997, 9, 264-269. (b) Yan, X.; Liu, G.; Liu, F.; Tang, B.; Peng, H.; Pakhomov, A.B.; Wong, C.Y. Angew. Chemie Int. Ed. 2001, 40, 3593-3596. (c) Tadd, E. H.; Bradley, J.; Tannenbaum, R. Langmuir 2002, 18, 2378-2384. (d) Wang, X.; Arsenault, A.; Ozin, G.A.; Winnik, M.A.; Manners, I. J. Am. Chem. Soc. 2003, 125, 12686-12687. (e) Garcia, C.B.W.; Zhang, Y.; Mahajan, S.; DiSalvo, F.; Wiesner, U. J. Am. Chem. Soc. 2003, 125, 13310-13311.

Polymer Coated Ferromagnetic Iron Ref \#6 Burke, N. A. D.; Stoever, H. D. H.; Dawson, F. P. Chem. Mater. 2002, 14, (11), 47524761.

Controlled Radical Polymerizationa Ref\# 7

Benoit, D.; Chaplinski, V.; Braslau, R.; Hawker, C. J. J. Am. Chem. Soc. 1999, 121, (16), 3904-3920.

Small Molecule Surfactants for Ferromagnetic Cobalt Ref\# 9

Puntes, V. F.; Krishnan, K. M.; Alivisatos, A. P. Science 2001, 291, (5511), 2115-2117. 